\title{
ANGIOCARDIOGRAPHY IN CYANOTIC CONGENITAL HEART DISEASE
}

\author{
BY \\ MAURICE CAMPBELL AND T. H. HILLS \\ From the Cardiac Department and the Department of Diagnostic Radiology, Guy's Hospital \\ Received August 25, 1949.
}

Radiological examination of the heart has been practised from the earliest introduction of $\mathrm{X}$-rays and gradually the importance of radioscopy, including the right and left oblique views, has gained ground as a valuable method of distinguishing the different chambers of the heart. In this country the method has been developed and applied largely by the teaching of Parkinson (1933 and 1936).

As early as 1931 Forssmann thought of the additional help that could be obtained in outlining the cavities of the heart after injecting opaque media by catheter. Laubry et al. (1935) injected hearts post-mortem and published some beautiful illustrations of the normal anatomy that found a useful basis for comparison with subsequent angiocardiograms. They showed the U-shaped right side and the window between the descending limb, formed by the right auricle, and the ascending limb, formed by the outflow tract of the right ventricle, with the right ventricle itself forming the horizontal base, and the right branch of the pulmonary artery an upper cross-bar.

In 1938 Castellanos, Pereiras, and Garcia showed some good angiocardiograms of children with congenital heart disease. They demonstrated the normal U-shaped curve of the right side, the window between the right auricle and the outflow tract of the right ventricle, and the post-stenotic dilatation of the infundibulum. Chavez et al. (1947) have given a summary of the gradual progress towards satisfactory angiocardiograms, referring particularly to the work of Ara, Cossio, Moniz, Carvalho and Saldanha, and Castellanos and Pereiras.

Angiocardiography was developed on a practical scale by Robb and Steinberg (1939) who published many illustrations of the additional information they obtained by this method. They found that the right auricle was shown at $1.5 \mathrm{sec}$. after the injection, the right ventricle and pulmonary artery at 2-3 sec., the pulmonary veins and left auricle at from 6 to $8 \mathrm{sec}$., and the left ventricle and aorta at from 8 to $10 \mathrm{sec}$. This work has been extended on a large scale in several centres in America.

Steinberg, Grishman, and Sussman have published a series of papers on angiocardiography in congenital heart disease, dealing particularly with a case of Fallot's tetralogy (1941), with dextrocardia (1942), with intracardiac shunts (1943a) with patent ductus arteriosus (1943b), and with the radiology of congenital heart disease $(1943 c)$. The paper on shunts is particularly pertinent to our present subject; 18 of the 65 congenital cases they had examined were thought to have shunts; 10 of these being through auricular defects and 2 through ventricular defects, and 6 due to an overriding aorta or one with some degree of dextro-position, 4 of these being regarded as Fallot's tetralogy and 2 as Eisenmenger's complex. Only two had post-mortem confirmation of the diagnosis.

They found the time of filling of the pulmonary vein and left auricle $(3.5-4.5 \mathrm{sec}$.$) and of the$ left ventricle and aorta $(5 \cdot 0-8.0 \mathrm{sec}$.) rather quicker than Robb and Steinberg, possibly because more children were examined. 
The main points they used to establish auricular septal defects were those that can be demonstrated on ordinary radioscopy, but in one case they thought there was additional evidence of revisualization of the right from the left auricle after it had already emptied. Once (Case 2) they obtained evidence of a left to right shunt through the ventricular septal defect by revisualization on the right ventricle. Most of these were, of course, shunts from the left to the right side.

They found that in ventricular septal defect with an over-riding aorta (Fallot's tetralogy) there was a right to left shunt shown by simultaneous visualization of the right ventricle, pulmonary artery, aorta, and sometimes the left ventricle, within two or three seconds. Their Fig. 4 is a good example of this, and their Fig. 5 is a less convincing example of Eisenmenger's complex.

They discuss whether the injection causes a rise of pressure sufficient to reverse a left to right shunt through an auricular septal defect and mention the filling of the I.V.C. and the hepatic veins (see page 68), and think that this reversal of the shunt may have taken place in one of their cases. They mention other difficulties. (1) A slow injection (one taking $2.5 \mathrm{sec}$. or more) or blood returning from the I.V.C. may refill the right side and so simulate a left to right shunt: the amount of diodone in the S.V.C. and its movement should be watched carefully from this point of view. (2) The circulation time may be so rapid that the left side fills more quickly than usual and this may simulate a right to left shunt. (3) A large right ventricle (or auricle) may allow too much dilution for good visualization. (4) Valvular stenosis may interfere with normal filling.

Roesler (1943) in his book on radiology of the heart gives some good illustrations but does not discuss congenital heart disease in any detail. He relates the best times for getting pictures of the different chambers of the heart with the ordinary circulation times and suggests that the superior vena cava and right auricle are best seen at $1.5 \mathrm{sec}$.; the right ventricle and pulmonary artery at 1 or $2 \mathrm{sec}$. less than the arm-lung circulation time, i.e. usually about $3 \mathrm{sec}$; and the left ventricle at 1 or $2 \mathrm{sec}$. less than the arm-tongue circulation time, i.e. generally about 6-9 sec. Sussman's Cardiovascular System in Clinical Radiology (1946) contains many good angiocardiograms, but does not discuss the special problems of cyanotic congenital heart disease in detail.

Chavez et al. (1947) produce excellent pictures of the anatomy of the heart, as the opaque substance was introduced direct into the heart through a catheter, thus enabling particular chambers to be studied in detail. They emphasize that very little of the pulmonary artery shows on the left border of the heart, though it forms the upper part of the right limb of the $U$; and that the right branch starts almost at a right angle to the main trunk and passes to the right; and the left branch, also going off at a right angle but passing almost directly backwards, sometimes shows as a "cap" on the top of the pulmonary artery as it turns backwards.

The left side of the heart is less pertinent to our present discussion as it is less well seen. It does not show any similar $U$ shape form and is, in fact, rather a long oval, nearly horizontal but somewhat larger in its left side, which slopes slightly downwards, this of course, corresponding to the ventricle and the right side to the auricle. The curved upper limit of the right auricle is well shown in their Fig. 9 and 11. The question of congenital heart disease is only dealt with incidentally but their Fig. 21 shows nicely the parallel curves of the aorta and of the pulmonary artery, with a slight space or indentation, a point that showed up well in several of our congenital cases and is illustrated in our Fig. 5 and 6.

Owing to the war little was done in England until the last few years, but work is now in progress at several centres, and some preliminary results have been published (Gardner, 1948; Brocklebank, 1948; and Keele, 1948).

With the wide experience that has been gained in America it may seem unnecessary to describe our much shorter experience. The results, however, of a somewhat new method are so favourable that it may be useful to give an account of our early findings which have already proved their value; all the more so as many workers are starting in this field.

In this paper we are describing the results obtained in the first 50 cyanotic cases. Since writing 
it we have seen an interesting report from Donzelot et al. (1949) on their similar experience, five of their cases being reported in some detail.

\section{APPARATUS AND MethoD}

The apparatus has been designed by one of us (T. H. H.) and has been described elsewhere (Hills, 1948). An X-ray tube is placed at a suitable height over a special trolley, just below the top of which is a $16 \times 16$ fluorescent screen. The image produced at this plane is recorded by a large roll-film camera, and direct light from other sources is excluded from the lens by a conical box which acts as a support for the screen and maintains the correct focal distance between camera and fluorescent image.

Exposures are made at the rate of one a second on a film of such width that the finished negatives are about $5 \times 5$ in. square. Fifty consecutive exposures could be obtained, but in practice the number is normally limited to fifteen. These small films cannot at present show the detail that can be seen on a full size film, but it is easier to make comparisons between four or eight films at once and this is important in interpreting results.

In children especially, where the circulation is rapid, much will be lost if the films are not taken quickly. The time taken over the injection must vary slightly, but is generally between one and a half and two seconds. When this is about half completed a start is made so that the first film is taken in another quarter of a second, i.e. a second or a fraction more after the start. This has generally shown the right auricle filling, but nothing else, and so has given a standard of the density of the rest of the heart and great vessels without any diodone, against which the filling can be seen readily.

The interval of one second between subsequent films is accurate as it is timed mechanically.

The opaque medium used is a 70 per cent solution of diodone in water. In view of its iodine content a preliminary sensitivity test is carried out; the patient is instructed to hold a few ml. of the solution in the floor of the mouth for about one minute, and any burning or tingling sensation completely contra-indicates injection.

Successful results depend on the intravenous injection of from 40 to $50 \mathrm{ml}$. of diodone or in adults up to $70 \mathrm{ml}$. in a maximum of two seconds, and to achieve this it is usually necessary to expose a vein in the arm and inset a wide gauge canula. Donzelot et al. (1949) say that the injection should be "brusque mais non brutale" to avoid spasm of the veins and too much dilatation with stagnation of the diodone. A preliminary injection of $20 \mathrm{ml}$. of saline demonstrates the suitability of the vein and the speed with which the injection can be made.

The patient is told to hold his breath during the injection and to expect an extreme sensation of heat. This follows some seconds after the injection and may be very unpleasant, but reaches its maximum rapidly and fades more slowly and has usually completely passed in two minutes. There is often a brief bout of coughing and during the next few minutes there may be some nausea. A proportion of the diodone injected will remain in the vein that is selected and the gradual arrival of this further volume in the heart must be remembered or it may confuse the interpretation of the films.

It is difficult to carry out this investigation in small or nervous children without an anæsthetic. The risks of the procedure and the precautions suggested are discussed later (see pp. 69 \& 70).

Direct or Oblique Views. We have used the A-P position mainly, in spite of the great value of the left oblique for many purposes. We thought that the A-P view gave fuller details of both pulmonary arteries and certainly of the systemic branches from the aorta-important information in patients who are going to have an operation. Probably it is best when pulmonary stenosis is a main part of the lesion, as in most of these cases. When relationships of the right and left ventricles are concerned, the left oblique view is certainly more valuable.

There are few cases where both views would not give useful information and this is the ideal; 
but, generally, we have hesitated to give two injections, though we have sometimes done so and have no reason to think this was the cause of death of one child (see p. 69).

Rise of pressure on the right side. One important question is how much the sudden injection of this amount of fluid can raise the pressure on the right side of the heart and so cause a right to left shunt. The pressure is certainly raised because the first films often show a reversed flow into the veins of the neck or across the innominate to the other side. Even more important, there may be a reversal of flow in the inferior vena cava and hepatic veins, which means that the raised pressure had spread through the right auricle. Some reversed flow has been a noticeable feature of nearly half our cases, all of these being children, where the amount injected is relatively greater; but there were many children who did not show it.

This filling of the veins may be noticed at one, but more often at two seconds; it rarely persists beyond the third second. There may be a reflux flow to the veins of the neck (Fig. 1) or across the innominate vein to the other side (Fig. 2A). Filling of the hepatic veins is well shown in Fig. 7A and 11 and to a lesser extent in Fig. 3. In Case 0208 it persisted rather longer than usual, and this may have been of significance as she was one of two patients who died.

These changes suggest that there might be a temporary reversal of a left to right shunt through an auricular septal defect, that might lead to an incorrect diagnosis. We have, however, no particular evidence of left auricular filling in cases where there was filling of the hepatic veins. Where we have found it, there have been other reasons for thinking that there was normally a right to left shunt. We believe, therefore, that this is rarely of importance, though it is a risk of misinterpretation that needs guarding against.
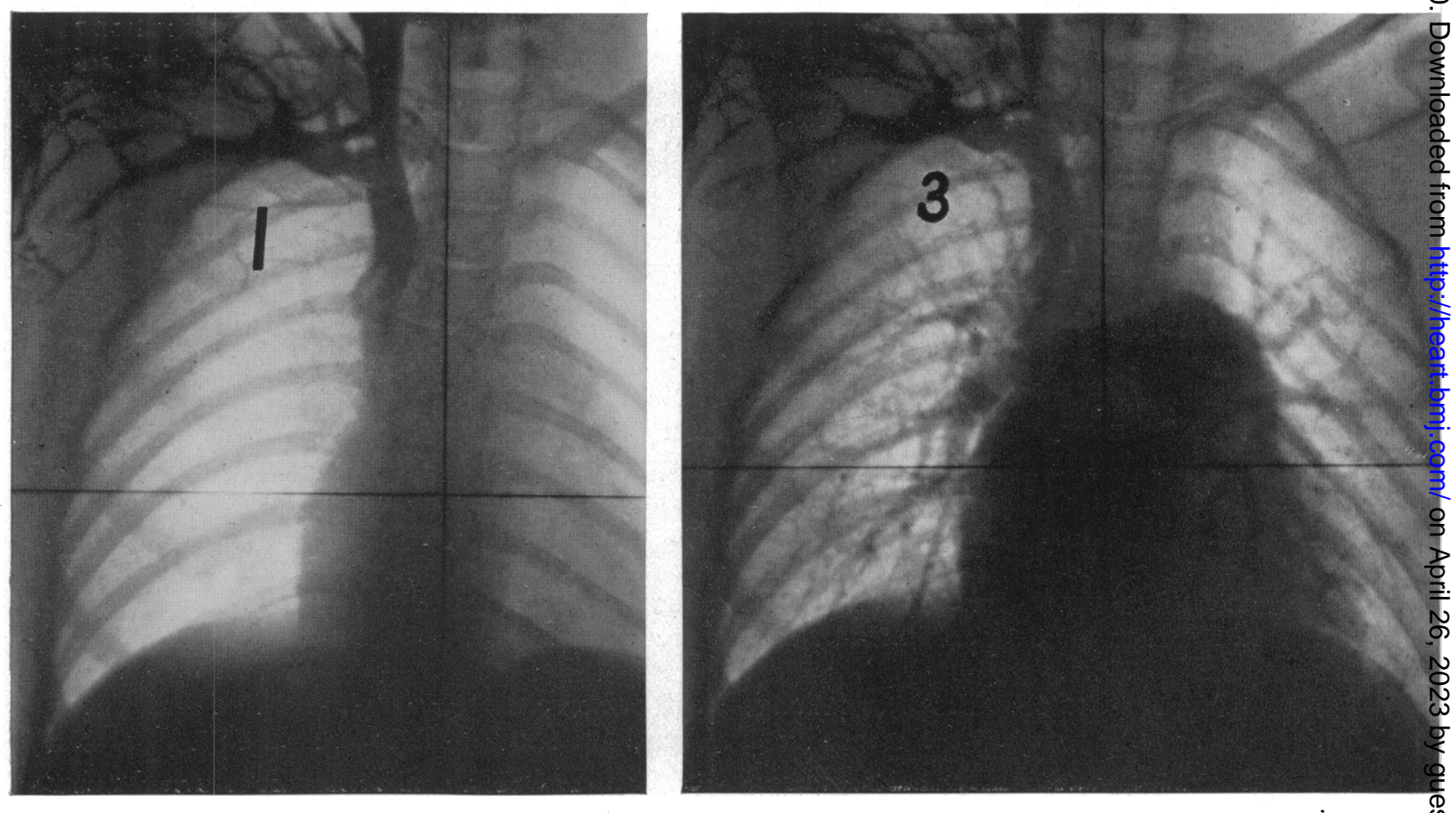

Fig. 1.-Normal filling of the pulmonary arteries for contrast with subsequent cases. It also shows reflux in the right jugular vein which has not disappeared by the third second.

(1) Diodone has filled the superior vena cava (s.v.c) and is passing into the right auricle. A good deal has flowed back into the right jugular vein and into other anastomotic veins.

(3) Right auricle, right ventricle, and pulmonary arteries are all well filled (as they were at 2 sec., but not so clearly). The main pulmonary artery is seen, dividing in the horizontal right branch and the left branch that passes backwards and is partially hidden. Smaller vessels in the lungs are already filled, with much increase in density. 
It is even more difficult to think that there can be a reversal flow through a ventricular septal defect or over-riding aorta, where the difference of pressure is so much greater.
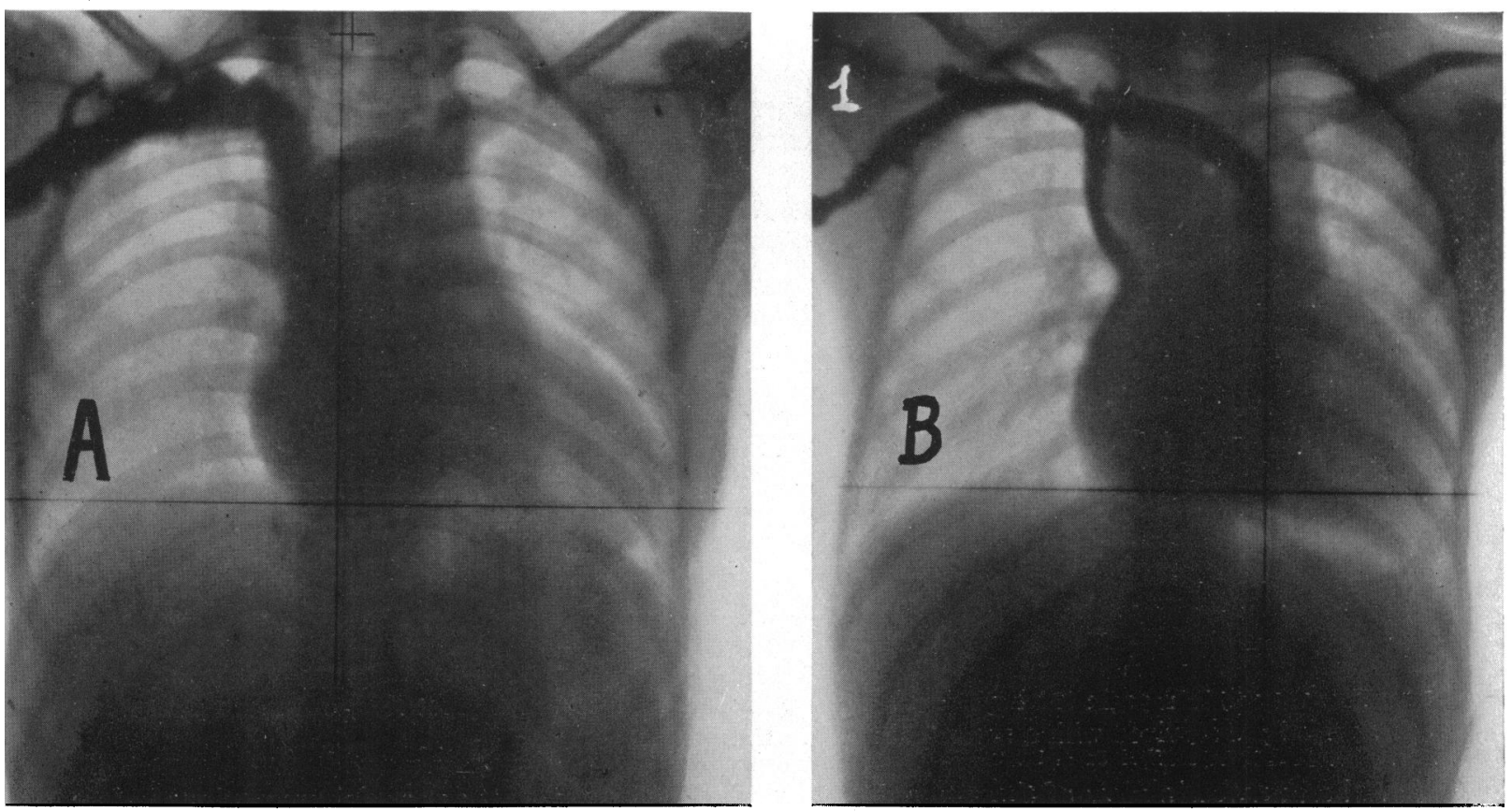

Fig. 2:-(A) Reflux filling of the innominate vein at 2 sec. Some diodone has passed into the right auricle. Fallot's tetralogy with an absence of lung filling. Case CB14.

(B) An anomalous double superior vena cava. Some dye has passed down the right s.v.c. at one sec. and can be seen lying along the outer border of the usual position of the right auricle: it tapers off and it is not certain that dye has entered the heart by this route. The main bulk has passed across to the other side and is passing downwards into the heart, possibly into the left auricle or into a common auricle. To the left of this there is a shadow that has not filled, possibly the left jugular vein entering the heart separately. The rightsided aortic arch occupies the right side of the space between. Case H126.

\section{THE RISKS OF ANGIOCARDIOGRAPHY}

Angiocardiography in cyanotic congenital heart disease is not free from risk. We had two deaths in the first thirty cases, but fortunately, there have been no other deaths in the next forty cases. Opinions have differed about the dangers of angiocardiography; we think that those who consider it free from risk have worked mainly with acyanotic and relatively fit patients, and that the risks are in the ill patients of the cyanotic group who have very little margin for any disturbance. Donzelot et al. (1949) appear to have had no fatalities in their cases, but think that a mortality of at least one per cent would be fully justified by the saving of life in subsequent operation and in the prevention of unnecessary thoracotomy.

A girl, aged 12, had Fallot's tetralogy with severe polycythæmia (Hb. 180 per cent). She had been in hospital some weeks. with pyrexia, and bacterial endocarditis had been suspected but not confirmed. She had been allowed up and seemed in her usual health. There was no special anxiety during the procedure and she had both P-A and oblique views taken after two injections. After these were completed, though she had not recovered consciousness, her condition did not alarm the anæsthetist. On return to the ward, however, her breathing became worse and she died about fifteen minutes after the injection, despite the administration of oxygen.

On the angiocardiograms the heart seemed larger than in most cases, but this had not been so previously 
and we wondered whether there was some dilatation. Nothing special was found post-mortem and there was no evidence of recent bacterial endocarditis. We felt on the whole that this was an anæsthetic death and hoped that if special precautions were taken and the oxygen continued for longer there would be no recurrence. Case CB14.

A girl, aged 14, had Fallot's tetralogy with disability and cyanosis of the highest grade and a hæmoglobin of 170 per cent, so that she was almost black and very breathless and only able to walk 10 yards. For some months she had been orthopnœic with increasingly frequent attacks of extreme cyanosis in which she was sometimes semi-conscious. The diagnosis seemed straightforward, but angiocardiography was done because it had been found increasingly useful by giving the surgeon beforehand the anatomy of the aortic branches and of the pulmonary artery. Again there were no special features to cause alarm during angiocardiography, which was done without a general anæsthetic after $2 \mathrm{~g}$. of phenobarbitone given two hours before. After the X-ray had been taken she complained of the usual hot flushing in the face, headache, and nausea. These failed to disappear as they usually did in 2-3 minutes and she retched and vomited a small quantity of fluid.

For the first 10-15 minutes she appeared to be improving, but then she lost consciousness and started stertorous breathing; she appeared spastic and her cyanosis increased. Oxygen was immediately given and artificial respiration was started. After the pulse had been absent for three minutes, the cardiac impulse became impalpable and the heart sounds inaudible. Cardiac puncture then showed no movement of the needle and 5 minims of $1 / 1000$ adrenalin were injected into the left ventricle. This started her heart beating again and artificial respiration and oxygen insufflation were continued. Despite this, and further intracardiac injection of adrenalin and nikethamide, no radial pulse ever became palpable, and after 40 minutes no cardiac action was demonstrable.

Post-mortem, the diagnosis of severe Fallot's tetralogy was confirmed, but there were no special findings to explain her death. We think angiocardiography should not have been done in such a very ill patient who had very little margin for anything. Operation would have been a great risk, but some patients as bad as this have survived with a successful result. Case 0208.

Subsequently, in view of these two deaths, we have taken at least as careful precautions before and after the general anæsthetic as for a major operation.

\section{Ancesthetic procedure}

Whatever anæsthetic is used must be given by an experienced anæsthetist with a liberal excess of oxygen. To ensure this it is better to forbid nitrous oxide completely. Cyclopropane appears to be at least as safe for these cases as anything else, and must be given in an efficiently closed system, to obviate risk of explosion.

The period of maximum danger seems to be the first fifteen minutes after the injection. The patient must be under the continuous personal supervision of the anæsthetist during the whole of this period, and oxygen must be administered by an efficient method. Sisters and nurses, however competent in dealing with ordinary cases, should not have this responsibility. The anæsthetist must personally accompany the patient back to bed, and satisfy himself that all is well before leaving him there. In most cases it is best to use an oxygen tent until full consciousness has been regained, especially when opiates have been given to control restlessness and there is, therefore, a risk of medullary depression.

\section{RESUlts OBTAINED}

This paper deals with fifty consecutive cases of cyanotic heart disease where angiocardiography has been carried out at Guy's Hospital; and the results have proved of interest and of clinica value. Two acyanotic cases have been included in the section on pulmonary valvular stenosis. The patients have been grouped according to the clinical diagnosis, though occasionally this had been changed by the special investigations. Most were selected by their supposed suitability for the Blalock-Taussig operation, as we have not in general felt it justifiable to carry out this investigation where the help in diagnosis was not likely to prove of practical value to the patient. 


\section{FALlot's Tetralogy}

The clinical diagnosis was thought to be Fallot's tetralogy in 31 cases.

Over-riding aorta. Evidence of a right to left shunt was obtained in all these thirty-one-in one (Case 0115 ) only after very careful examination. In all the others this shunt was easy to demonstrate, and the aorta and its branches filled so quickly and freely (Fig. 3) that it seemed much more
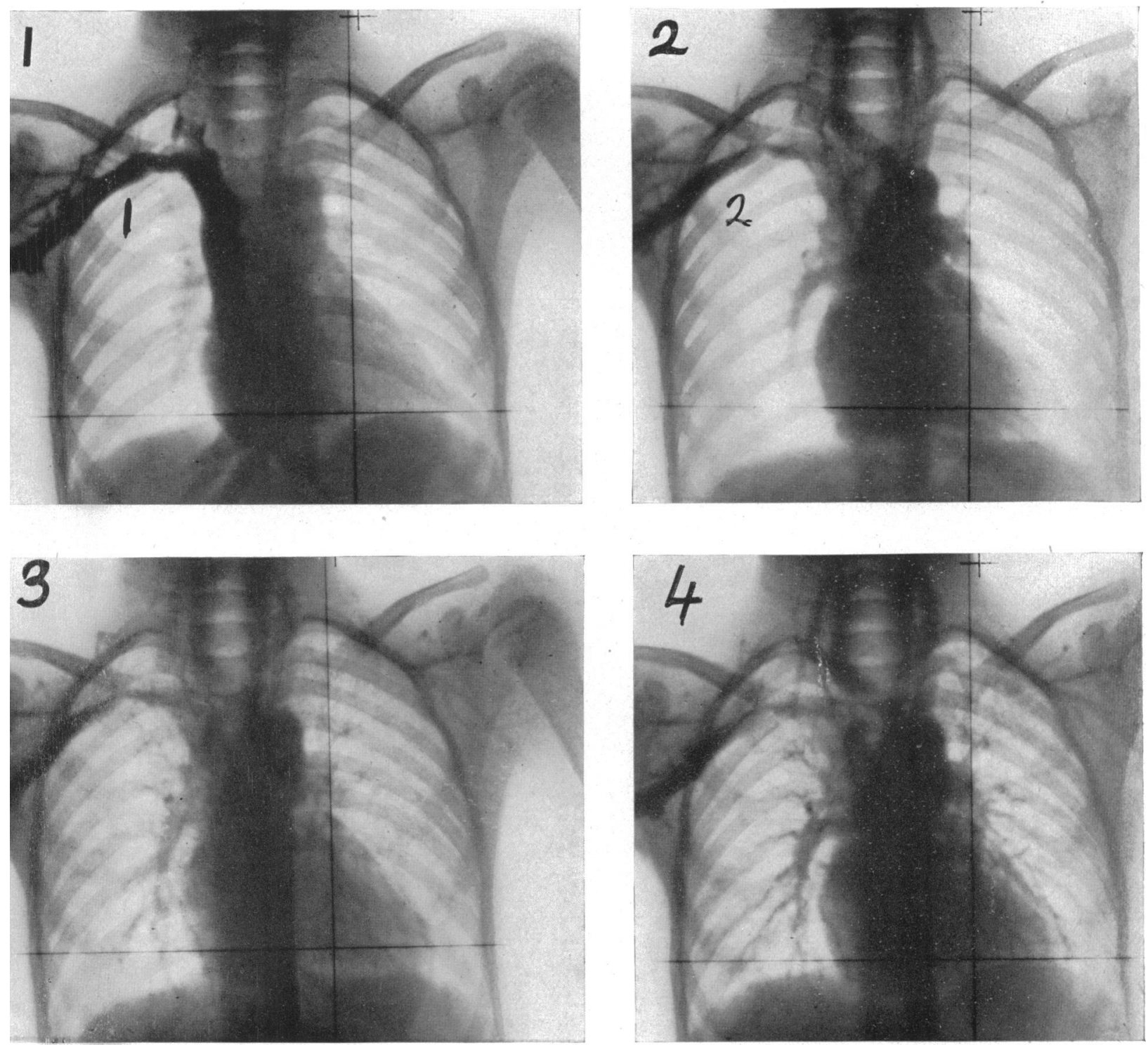

Fig. 3.-A series of angiocardiograms from a case of Fallot's tetralogy with a gross right to left shunt and moderate pulmonary stenosis.

(1) At 1 sec. the right auricle is well filled and possibly some diodone has already reached the right ventricle and aorta. Reflux into the hepatic veins can be seen.

(2) At $2 \mathrm{sec}$. the right ventricle and the aorta and its branches in the neck are much more clearly seen, and a faint shadow of the subclavian has already appeared. Both pulmonary branches can be seen, and below the left pulmonary there is a shadow that is probably a dilatation of the infundibulum above the stenosis.

(3) At 3 sec. the aorta is clearly seen, and the subclavian is better seen.

(4) At 4 sec. the aorta and subclavian are still well seen, and the lungs are now filling. Case 0053. 
likely to be due to an aorta that over-rode the right ventricle than to one that filled entirely from the left ventricle with the right to left shunt through a septal defect, quite apart from the direct observation in many cases that the left ventricle showed no signs of having filled.

Generally, the right to left shunt was described as large (18 cases) or moderate (12 cases); only in the one already referred to was it described as slight and then could not be seen till 4 seconds. As a rule the aorta was well filled at 2 seconds ( 20 cases) but sometimes not till 3 seconds (10 cases). The amount seen in the aorta and its branches seemed a better guide than whether the aorta could first be seen clearly at 2 or at 3 seconds.

At first, we were impressed by the ease with which filling could be seen in the abdominal aorta and the renal artery, but later, because of the importance of the anatomy of the neck vessels, have taken films at a higher level, so that the innominate, carotid, and subclavian have been the branches most noted. The filling of the subclavian on the side opposite to that used for the injection is of particular value and is often well seen at the third and fourth or even the second second (Fig. 4).

We have little experience of similar angiocardiograms in normal subjects for comparison; a subclavian that is filling in the normal way after circulation through the lungs cannot generally
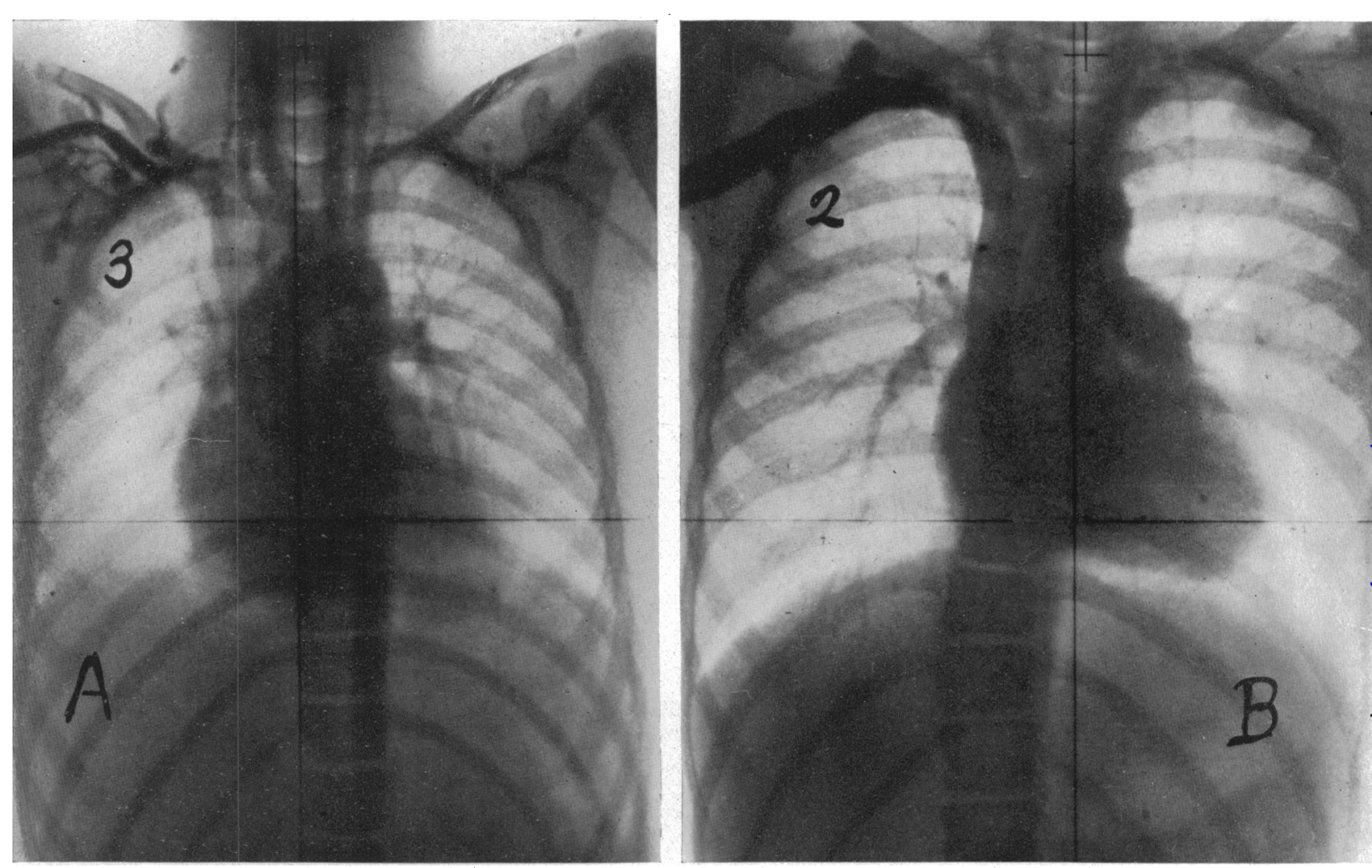

Fig. 4.-Angiocardiograms from two typical cases of Fallot's tetralogy.

(A) The right auricle and ventricle are both seen at 3 sec., but the main feature is the over-riding aorta, so uncoiled that the ascending arch and descending part can easily be seen, and also well below the diaphragm. The innominate, carotid, and subclavian arteries are well shown, and probably the vertebral arteries, but there is little detail about the infundibular region or pulmonary arteries, though that on the left is seen. Case P046.

(B) The right auricle, right ventricle and the aorta and its branches are shown at $2 \mathrm{sec}$. The left subclavian is seen less clearly, and probably the left internal mammary artery. The dilatation of the infundibulum beyond the stenosis is clearly seen below the left-sided aorta. The right pulmonary artery is visible, but the left is hidden posteriorly. The contrast between the uncoiled aorta in (A) and the vertically placed aorta in (B) is striking. Case 0107. 
be seen until 6 or 7 seconds, even in children; though Dr. Frances Gardner informs us that she has found it happening within 4 seconds in a small child.

In straightforward examples where the clinical diagnosis of rather severe Fallot's tetralogy was confirmed by other methods, the results of angiocardiography seemed clear and decisive. Typical reports were as follows.

The right auricle fills at a normal rate. Dye is seen in the aorta at three, and in the right renal artery at six seconds. The pulmonary arteries are never well filled and show maximum concentration at five seconds. There is a considerable volume shunt from right to left and a major degree of pulmonary stenosis. Case 0105.

The right auricle is well outlined at two seconds. At three seconds dye is seen in the pulmonary arteries, and the aortic arch, and is already filling the left subclavian artery. The lung fields show little increase in density throughout the series. A considerable right to left shunt and marked pulmonary stenosis. Case 0185.

The dye outlines a normal right auricle. There is a large right to left shunt outlining an over-riding aorta two seconds after the end of the injection. The pulmonary arteries are best filled at four seconds, but the concentration is poor. Case CB09.

The second of these is shown in Fig. 5B and the aorta, pulmonary artery, and dilated infundibulum can be well seen, forming the three main features going downwards. Fig 5A shows what

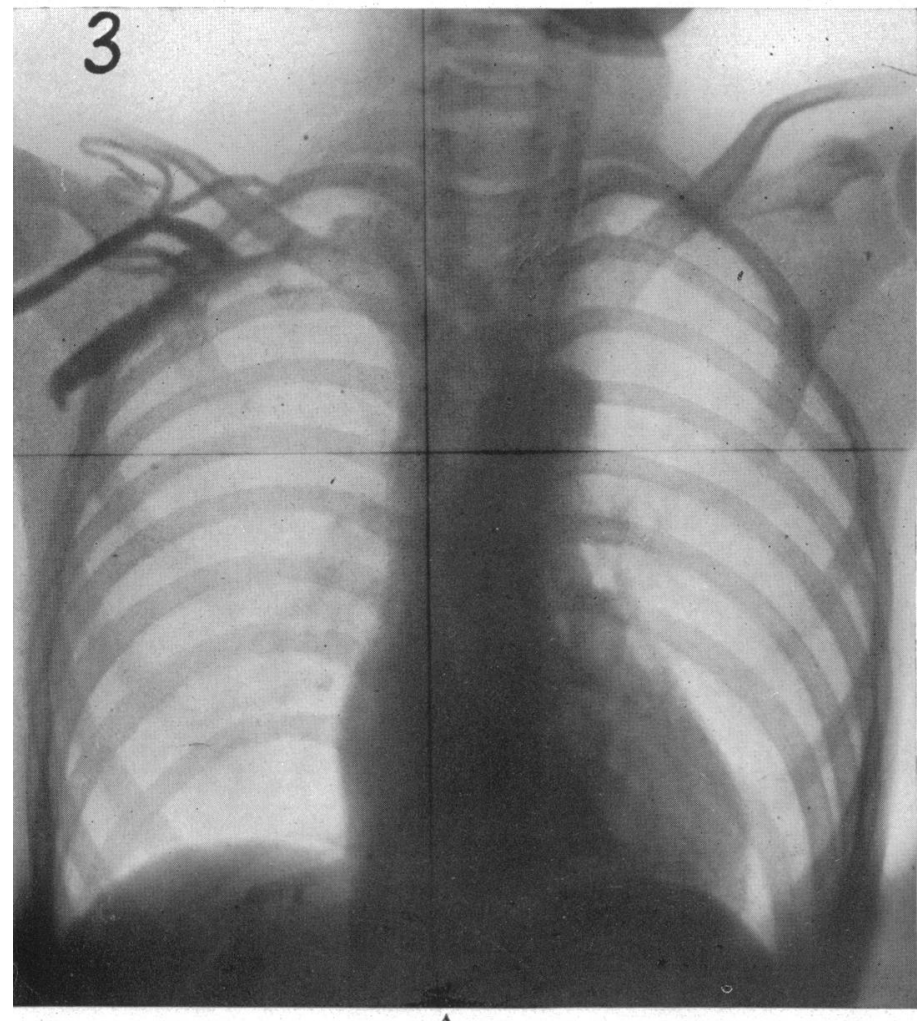

A

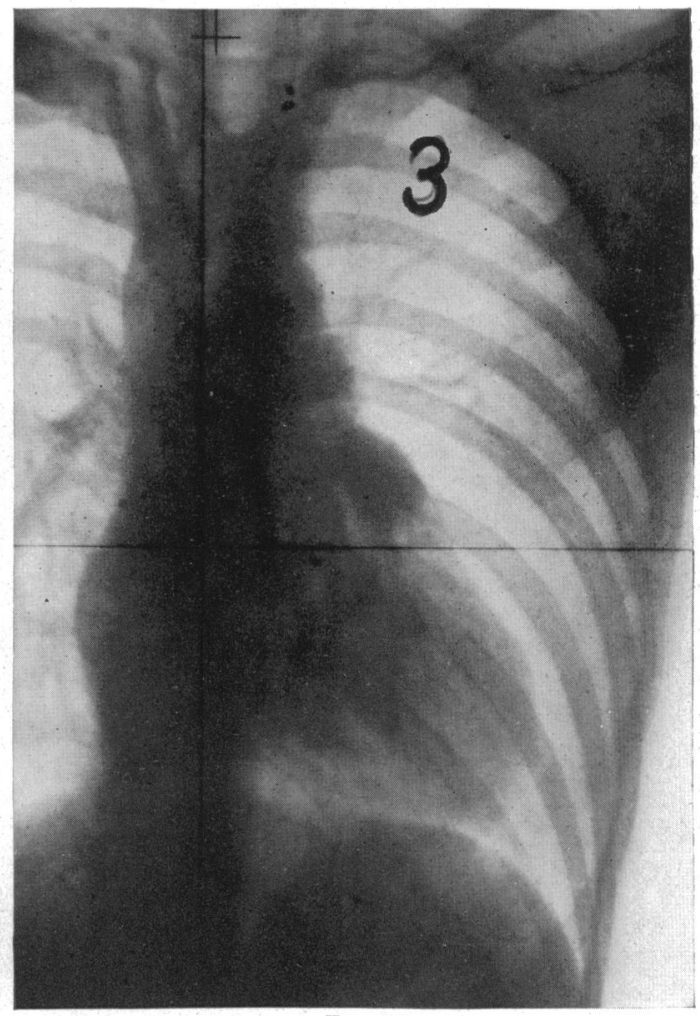

B

Fig. 5.-Angiocardiograms at $3 \mathrm{sec}$. in two contrasted types of Fallot's tetralogy. The right auricle and right ventricle are filled in both.

(A) represents what we have called the " dull " picture because the high grade pulmonary stenosis prevents much marking in the lungs, and there is little to see except the quickly filled over-riding aorta and its branches. Case 0208.

(B) shows a more interesting picture, where the infundibular dilatation beyond the stenosis can be seen below the left pulmonary branch, which is itself below the aortic knuckle. These three, with the lighter outline of the left ventricle, form four distinct arcs on the left border of the heart. Case 0185. 
we have called the " dull " picture of Fallot's tetralogy where the high grade stenosis prevents any real increase in the pulmonary arterial shadows, and there is only the over-riding aorta. This variety is much more common than would be thought on the illustrations chosen, as owing to their close resemblance few have been reproduced.

Pulmonary stenosis. Angiocardiography seemed less decisive or at least more difficult as regards the diagnosis of pulmonary stenosis. In Fallot's tetralogy the outflow tract of the right ventricle is of very variable shape, as can be seen from the figures. In some cases one sees nothing more than the border of the right ventricle and the pulmonary artery itself, and has to judge the stenosis solely by the degree of filling of the lungs (Fig. 5A). In others, a rounded shadow may be seen that appears to be the dilated infundibulum distal to the stenosis (Fig. 5B).

In these 31 cases this shadow could be seen easily in 12 (Fig. 3, 4B, 6, 7, and 8) with less certainty in 6 , and could not be recognized in 13 (Fig. $2 \mathrm{~A}$ and $5 \mathrm{~A}$ ). Sometimes this same shadow can be seen on the straight $X$-ray though then, of course, it is not so certain what it is. Fig. 7 gives a good example of two rounded shadows one of which could be seen on the straight $X$-ray while the other could not.
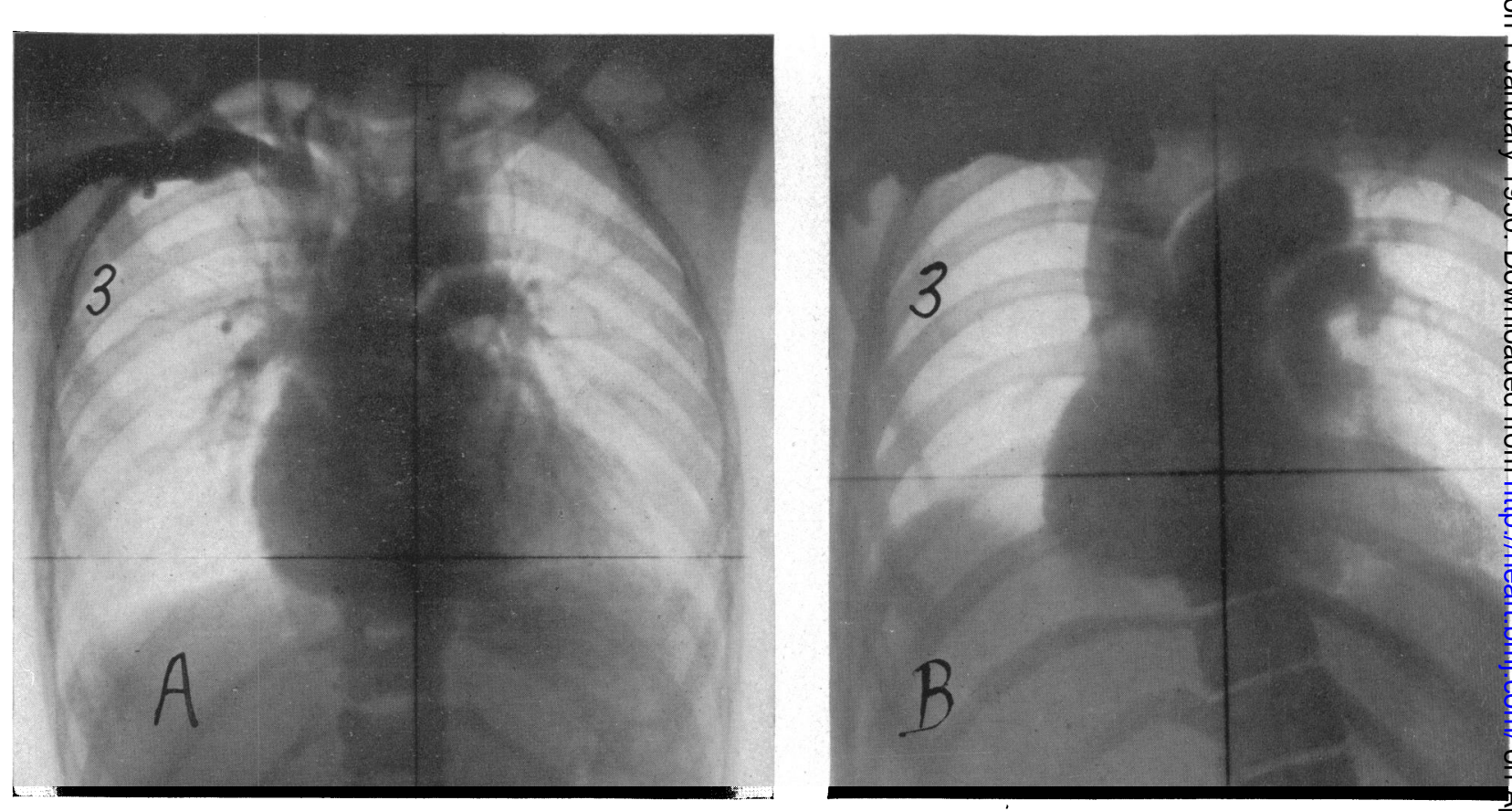

Fig. 6.-Two cases of Fallot's tetralogy, where the aorta is wide and the arch horizontal, with the left pulmonary branch forming a second arch below this. Although the pulmonary artery is well seen there is little filling of the lungs. Both are taken at 3 sec.

(A) Dilatation of the infundibulum beyond the stenosis which passes directly to the right pulmonary branch, with the left pulmonary branch going off at an acute angle and lying just below the aortic arch. Case 0089 .

(B) The right ventricle seems denser than the right auricle, and the left ventricle is not filled. The shadow above the stenosis is well seen, but this infundibular dilatation in contrast with (A) seems to pass more directly to the left pulmonary branch and the right is hardly seen. Case CB12.

We have estimated the degree of stenosis by the amount of filling of the pulmonary arteries and of the lungs, apart from this evidence of a dilatation beyond the stenosis. The mere fact of the pulmonary arteries filling at two seconds at the same time as the aorta is no evidence against pulmonary stenosis. If there is much pulmonary blood flow there will be a steady increase in the density of the lung fields and this would appear to be a better guide than the condition of the main pulmonary arteries, though these, too, are of some value. 
The estimate of the degree of pulmonary stenosis was made entirely by one of us (T. H.) who at the time was unaware of the clinical diagnosis, so that it was based entirely on the angiocardiograms. Finally, the degree of pulmonary stenosis was arbitrarily classified, again by T. H., into six grades, five suggesting almost pulmonary atresia, and one little or no pulmonary stenosis.

The 31 cases in this group were classified as follows-grade 4 or above, eight; grade 3, nine; grade 2, eight; and lower grades than this, six cases. Of the six who died four had grade 3 pulmonary stenosis or more, and two had grade 2 stenosis only. Even in these two it was considerable, as the infundibular stenosis diameter measured between 3 and $4 \mathrm{~mm}$. only in one and was described as slit-like in the other (Fig. 8).

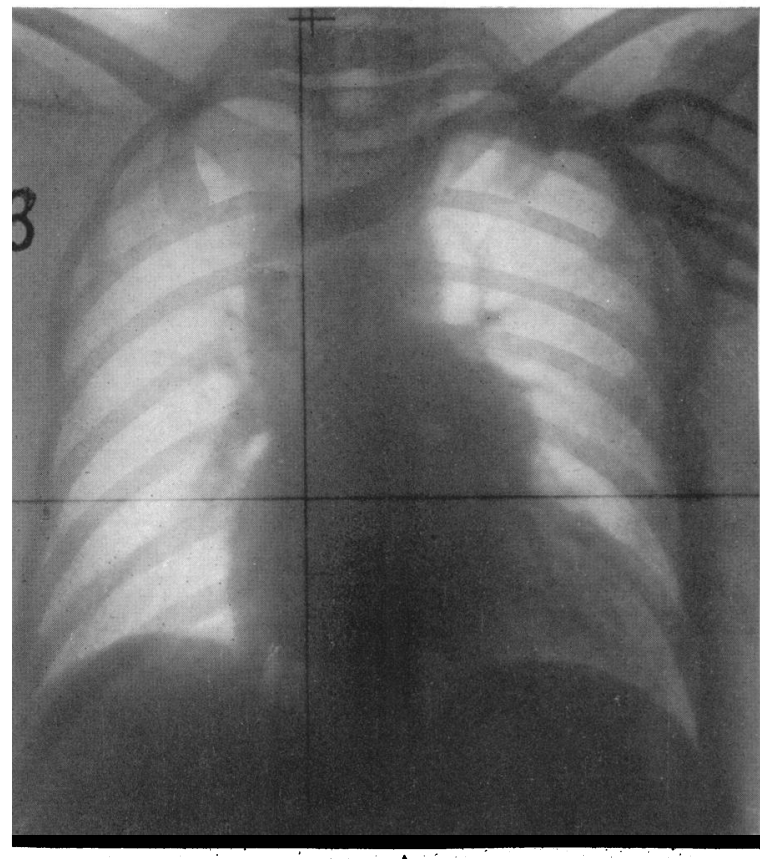

A

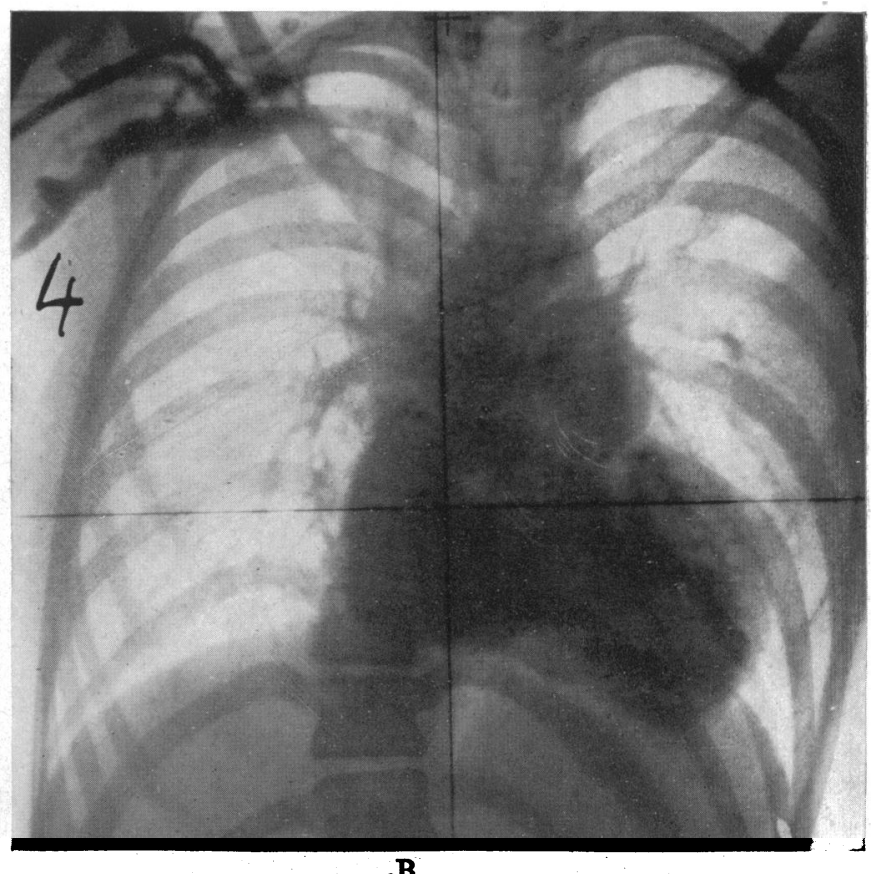

B

FIG. 7.-Two cases of Fallot's tetralogy with considerable dilatation of the infundibulum.

(A) The aorta is less well seen than in many cases at 3 sec., suggesting that there may be a smaller right to left shunt than usual. The infundibular dilatation could be seen on a straight X-ray, but its nature was less certain. There is extreme pulmonary stenosis. Case CB11.

(B) The over-riding aorta is well seen at 4 sec., and the rounded shadow which includes the dilated infundibulum and pulmonary artery fills the hollow below the arch. It could not be recognized easily on a straight Xray, perhaps because of the severe scoliosis. Case 0080.

We do not feel satisfied that the degree of pulmonary stenosis can be assessed in this way. There were 16 cases where cardiac catheterization allowed a calculation of the pulmonary blood flow, though this too, is only an estimate. In eight of these with grade 4 or 5 pulmonary stenosis, catheterization suggested an average pulmonary flow of 44 per cent of normal; in six with grade 2-3 pulmonary stenosis, 50 per cent of normal, and in two with grade 1 or 2 pulmonary stenosis 57 per cent of normal. Considering the wide range of the individual figures these average differences are not very significant. In one patient where hesitation was felt about operation because the pulmonary stenosis was thought to be so slight, the relatively high figure of 70 per cent of a normal pulmonary blood flow was found.

Of the 25 cases with pulmonary stenosis classed as grade 2 or above, 18 have already had a successful operation and only one had a completed operation that produced relatively little improvement, probably because of surgical difficulties (P056). 


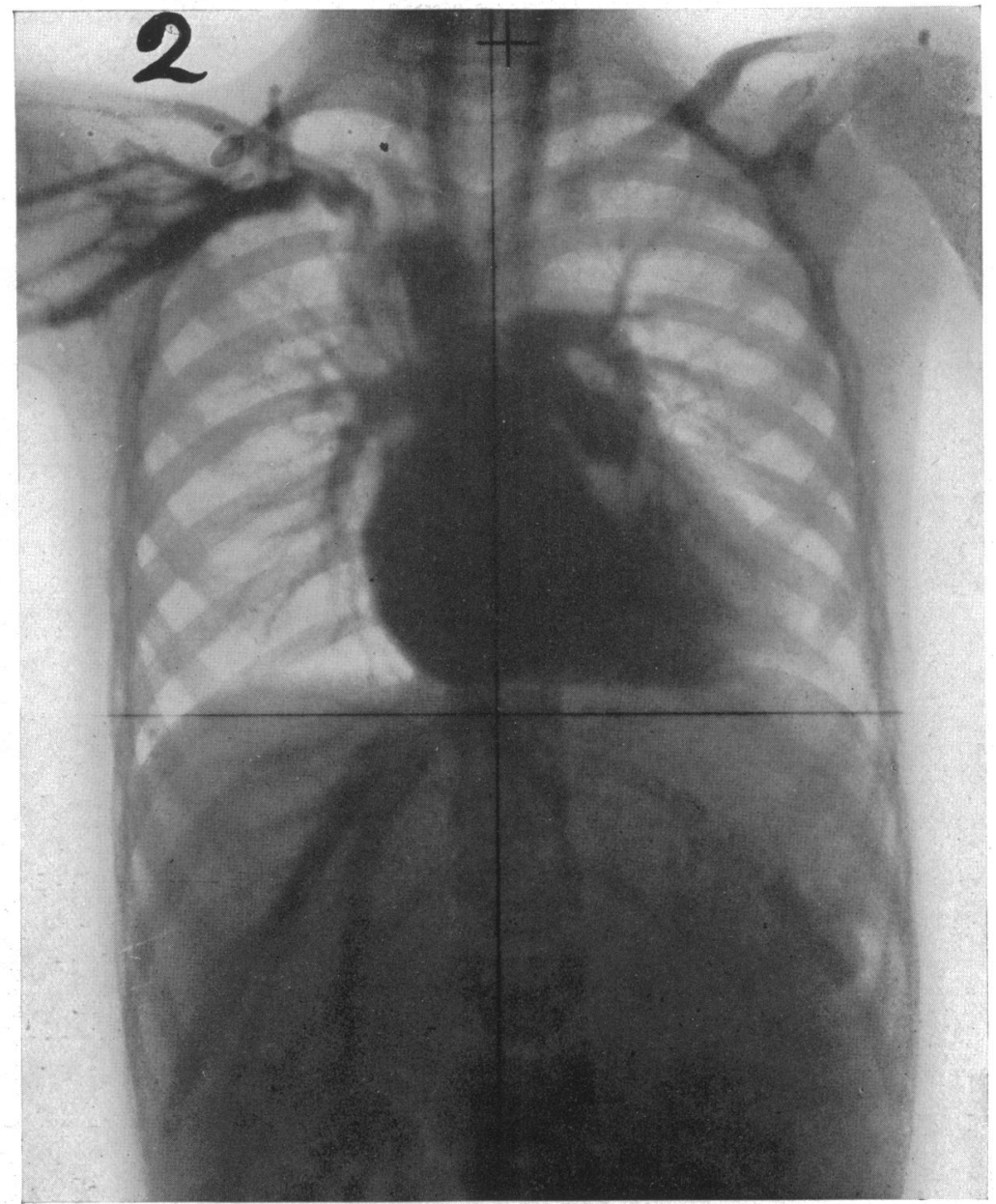

FIG. 8.-Fallot's tetralogy; showing dilatation of the infundibulum beyond the stenosis. The diagnosis was confirmed post-mortem. At 2 sec. the right auricle and ventricle are well filled, and a right-sided aortic arch. There is considerable dilatation beyond the infundibular stenosis, and both pulmonary branches are well seen, but the lungs do not fill much. Retrograde filling of the hepatic veins is well shown. Case P023.

Cases with less evidence of pulmonary stenosis. There remain the 6 cases where the degree of pulmonary stenosis was thought to be less than usual, between grades 1 and 2 ( 4 cases) and between 0 and 1 ( 2 cases). It is interesting as showing our growing reliance on angiocardiography that two of these cases occurred early and no hesitation was felt about operating. The other four were seen later and it was only after much thought and further observation of the patients that it was decided to operate. We were encouraged in this by the great improvement in the two former patients, both in their capacity for exertion and in their colour. detail.

The two cases where there seemed least evidence of pulmonary stenosis are described in more

A girl, aged 8, was moderately cyanosed, but had attacks of deep cyanosis in which she went semiconscious. These were getting worse, so that walking along the ward might provoke an attack, sometimes with complete loss of consciousness. Cardiac catheterization showed increased pressure, $80 / 10 \mathrm{~mm}$. $\mathrm{Hg}$. in the right ventricle, but the pulmonary artery was not entered. Angiocardiography showed a high degree of over-riding aorta (Fig. 9). This was the first case where refilling of the subclavian artery was observed 
after the dye had been through the lungs; and as this occurred at six or seven seconds, it was felt that there was no significant pulmonary stenosis. Operation was decided on after much hesitation, but so far (six months) she appears greatly improved. Case 0042.

A boy, of 18, had moderate cyanosis from birth, and severe disability. Clinically, he seemed a typical example of Fallot's tetralogy. On screening the lung fields were more dense than usual, but we thought that the lungs were oligæmic and that he was suitable for operation. On angiocardiography he was at first thought to have no pulmonary stenosis, but finally a very slight degree. He was, therefore, an excellent test case for the value of operation in this group and other patients were delayed pending the result of his operation.
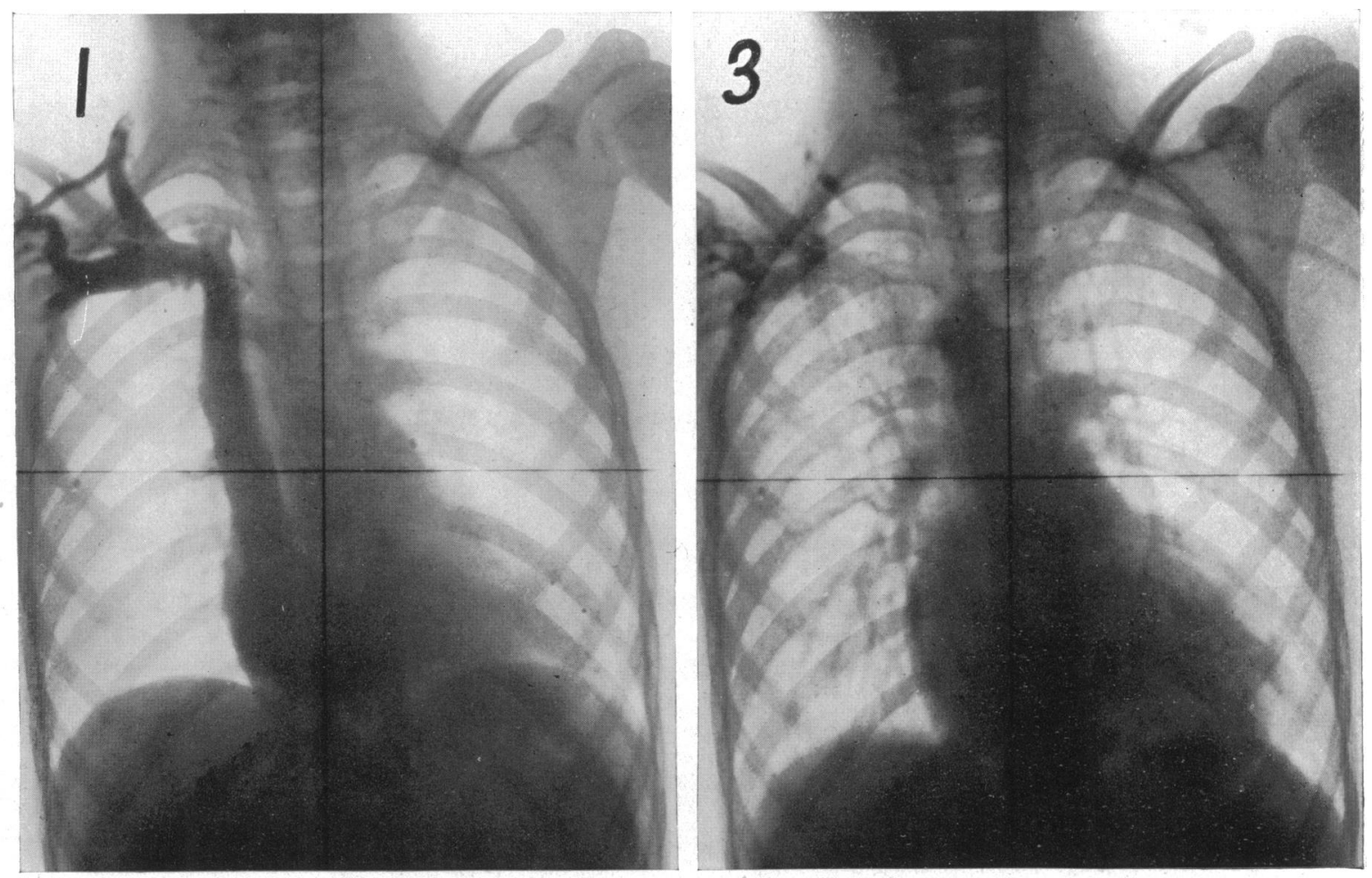

FIG. 9.-Fallot's tetralogy with a gross right to left shunt and minimal pulmonary stenosis.

(1) At 1 sec. the right auricle is filled, and the right ventricle to a slight extent.

(3) At $3 \mathrm{sec}$. the heart is better filled. The right-sided aorta is easily seen, and its branches, and the leftsubclavian, specially clearly, indicating an over-riding aorta, which was already well seen at 2 sec. The pulmonary arteries are also well filled, and the lung fields, as a whole, are filling.

The subclavian artery, which had completely disappeared by 5 and 6 sec. showed up again at 7 sec. with blood that had circulated through the lungs. Case 0042.

Ten weeks after, the result was extremely good. He was at school and getting about normally all day. He had already walked a mile with ease compared with the 200 yards that he had been able to walk previously. His colour was almost normal except for slight cyanosis in the nails. On screening, both pulmonary arteries were seen more easily than in most cases after operation, and pulsation could now be seen in both branches. There was, however, no congestion of the lungs and no undue increase in the size of the heart. His progress was equally good after eight months. Case 0067.

In these two cases the pulmonary stenosis was probably much less than usual, and the disability more due to the over-riding aorta taking the bulk of the blood. In general, the operation seems to have produced as much improvement in those thought to have slighter grades of pulmonary stenosis. This at first sight is rather surprising. It may be that our estimate of the relative degrees 
of stenosis is not correct, but we think it indicates that a subclavian-pulmonary anastomosis is helpful for the abnormality produced by the over-riding aorta, re-directing to the lungs some of the blood that should have gone there direct, though, possibly with a greater risk of susbequent cardiac enlargement from the increased work.

Except in six cases where the pulmonary infundibular stenosis was confirmed after death, there is of course, no absolute proof of its presence, but the other evidence supports it.

\section{Case Somewhat Resembling Fallot's Tetralogy}

A girl, aged 7, was thought to have Fallot's tetralogy, but was unusual in the absence of a systolic murmur and in some increased density of the lung roots, which it was thought might be due to collateral vessels. (Case P048.)

On angiocardiography there was early filling of the left ventricle and the aorta filled before the pulmonary arteries. The lightness of the lung fields supported pulmonary stenosis, though the right lung filling better than the left suggested a right-sided patent ductus. There was no clinical evidence of this and we should have suspected large bronchial arteries. There seemed to be atresia of the left pulmonary artery, but radioscopy suggested that there might be a vessel here that would be adequate for an anastomosis.

The interpretation of the angiocardiogram was correct in this particular, and at operation the left pulmonary artery seemed atresic and no anastomosis could be performed. After her death the findings were still difficult. The blood supply to the lungs was through dilated bronchial arteries; at first, she was thought to have a common arterial trunk, but finally an atresic pulmonary artery was found.*

\section{Fallot's Tetralogy or Pulmonary Atresia with Patent Ductus or Bronchial Arteries}

There were five patients where the clinical picture of Fallot's tetralogy was associated with signs suggesting a patent ductus arteriosus. These cases will be given very shortly as others have been investigated since and raise problems that can be discussed best on a larger number. A continuous murmur may be produced by enlarged bronchial arteries, and lungs filling in this way may often be recognized. The cases fall into four groups, Fallot's tetralogy or pulmonary atresia both with a patent ductus, or pulmonary atresia or a common arterial trunk, both with enlarged bronchial arteries. It is difficult to distinguish the last two conditions.

One of these (Case 0021) is being fully reported as post-mortem there was pulmonary atresia with the blood supply to the lungs through a patent ductus (Allanby, Brinton, Campbell and Gardner, 1950). Although it was not recognized at first, as the right to left shunt was thought to be through a ventricular septal defect, she was a good example of an auricular septal defect with the rather horizontal curve of the upper border of the left auricle showing clearly (Fig. 10).

A second (Case P021) had signs of patent ductus on the right (with a right-sided arch) and much more blood flow to the right lung than to the left, with a dilated pulmonary artery on the right side. This was obvious on ordinary $\mathrm{X}$-rays and more so on angiocardiography. An over-riding right-sided aorta filled at 2 seconds. There was so little filling of the left lung (Fig. 11) that operation was performed on this side with some anxiety as to whether any pulmonary artery suitable for anastomosis would be found. Fortunately, in spite of the poor filling, the artery was of reasonable size, though thin-walled, and a good anastomosis could be carried out. Pulmonary atresia cannot be excluded, but the pulmonary root shadows were not nodular and the left pulmonary artery found at operation also seemed rather against this.

The third (Case 0087) seemed much the same clinically, except that the ductus murmur was on the left and the lung filling seemed to be nodular rather than through a normal pulmonary artery. It was hoped that he had Fallot's tetralogy with a patent ductus, though the exaggerated sabot-

* Now that the necropsy findings are known it would be easy to present this case in a simpler form. We have, however, felt in this and other instances that the difficulties and mistakes that have arisen will be useful, and have left the picture as it appeared clinically. 
shaped heart with the deep pulmonary bay and the nodular filling suggest pulmonary atresia. On angiocardiography the aorta filled at 3 seconds, showing a gross right to left shunt. The arch was high and left-sided, but there was an additional vessel on the right, a large innominate or possibly a remnant of a partial right-sided arch. The pulmonary shadows did not show any filling till 4 seconds and the upper right lung became denser than the left, with no evidence of normal right or left main pulmonary arteries (Fig. 12).
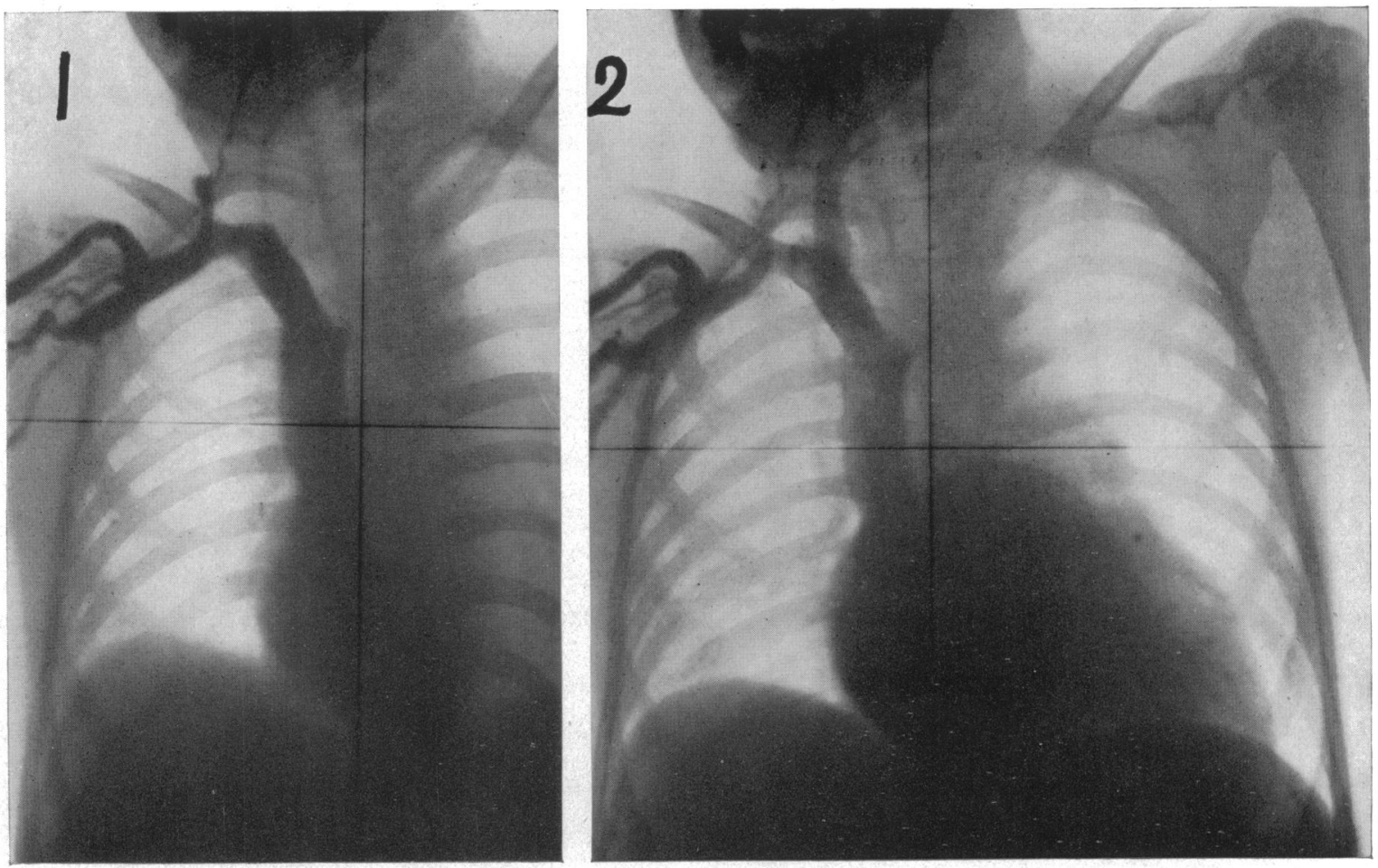

FIG. 10.-Filling of the left auricle in pulmonary atresia with a closed ventricular septum.

(1) At $1 \mathrm{sec}$. the right auricle is filled.

(2) At $2 \mathrm{sec}$. the diodone has passed over to the left, and the almost horizontal curved upper border is typical of filling of the left auricle. The aorta cannot yet be seen. Case 0021 .

At operation conditions seemed very abnormal and no pulmonary artery to which an anastomosis could be made was found. There appeared to be a vessel arising from the upper side of the subclavian or innominate and coursing downward into the lung; looking back at the films, this could be made out. We think now that this nodular appearance where the left pulmonary artery should be, with filling of the lung high up on the right side means an absence of the main pulmonary trunk, the lungs getting their blood supply from the aorta through bronchial arteries. ${ }^{*}$ The final diagnosis is pulmonary atresia or possibly a common arterial trunk (though the narrowness of the shadow is against this) with the lungs filling from the bronchial arteries.

The fourth (Case 0191) was similar clinically and on angiocardiography, but the evidence was less clear and she was not submitted to operation.

The fifth (Case 0181) need not be discussed, as clinical examination, catheterization, and angiocardiography (made more difficult by her being 25 years of age and overweight) have failed to produce reasonable certainty about the diagnosis.

* Frances Gardner has independently emphasized these two features as characteristic of hypertrophied bronchial arteries and we have borrowed the word " nodular" from her description. A series of such cases is being reported (Campbell and Gardner, 1950). 

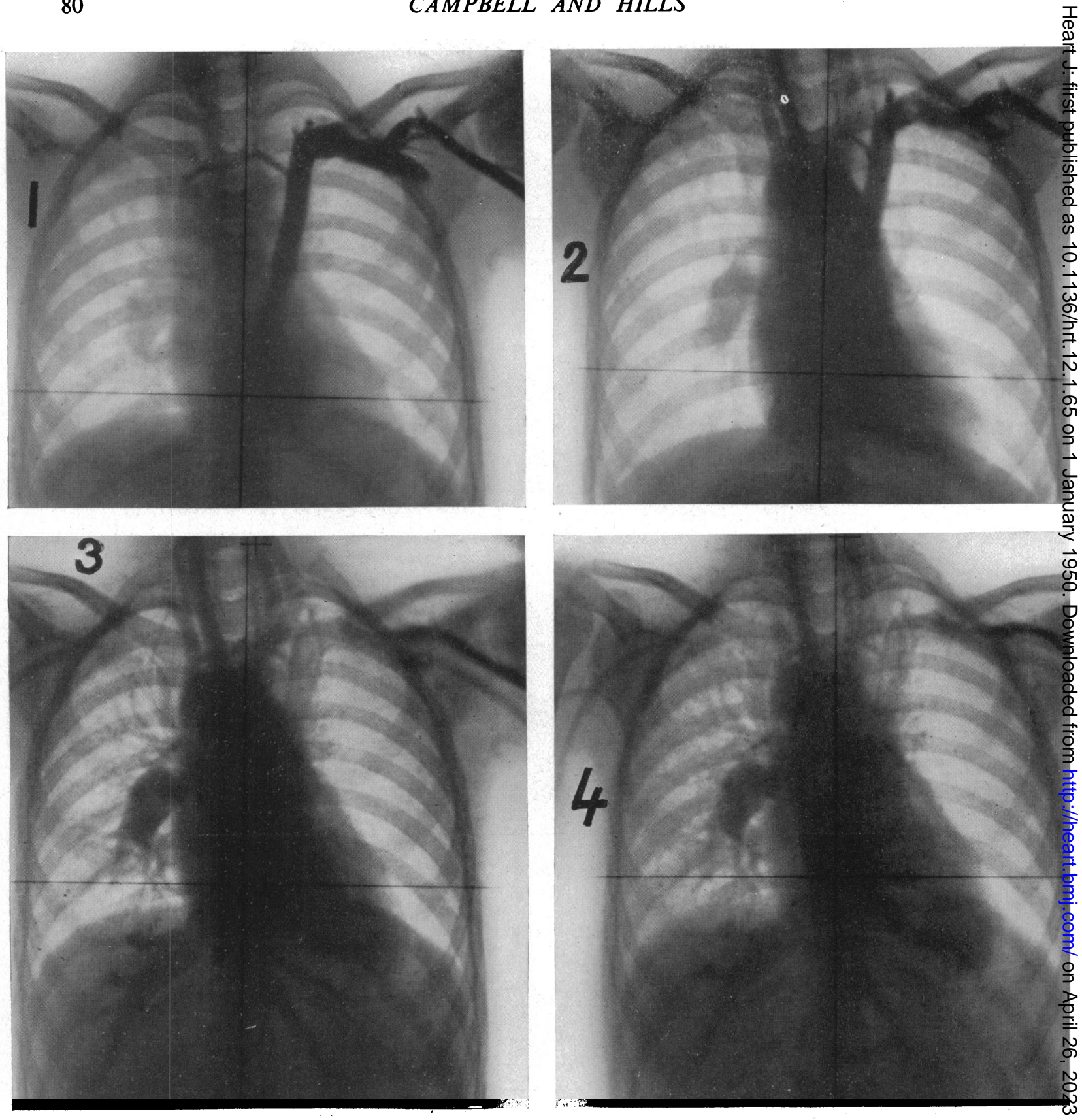

FIG. 11.-Fallot's tetralogy with a right-sided patent ductus arteriosus.

(1) At 1 sec. the left-sided s.v.c. is well seen, filling the left side of the right auricle. A fine trickle passes across the innominate vein to the right side, and catheterization had shown that there was also a s.v.c. on the right.

(2) At 2 sec. the right auricle, right ventricle, and right-sided aorta and its branches are filled. The dilated right pulmonary has filled a little, but probably through the patent ductus, as it does not seem to connect with the main shadow of the heart.

(3) At $3 \mathrm{sec}$. the same features can be seen in the heart which is now more obscured, and also the subclavian and some reflux to the hepatic veins. The dilated right P.A. is now much fuller and the right lung is becoming dense, but there is very little filling of the left lung.

(4) At $4 \mathrm{sec}$. the aorta and dilated P.A. are less dense, though there is more general filling of the right lung. The subclavian is still well seen. Case P021. 

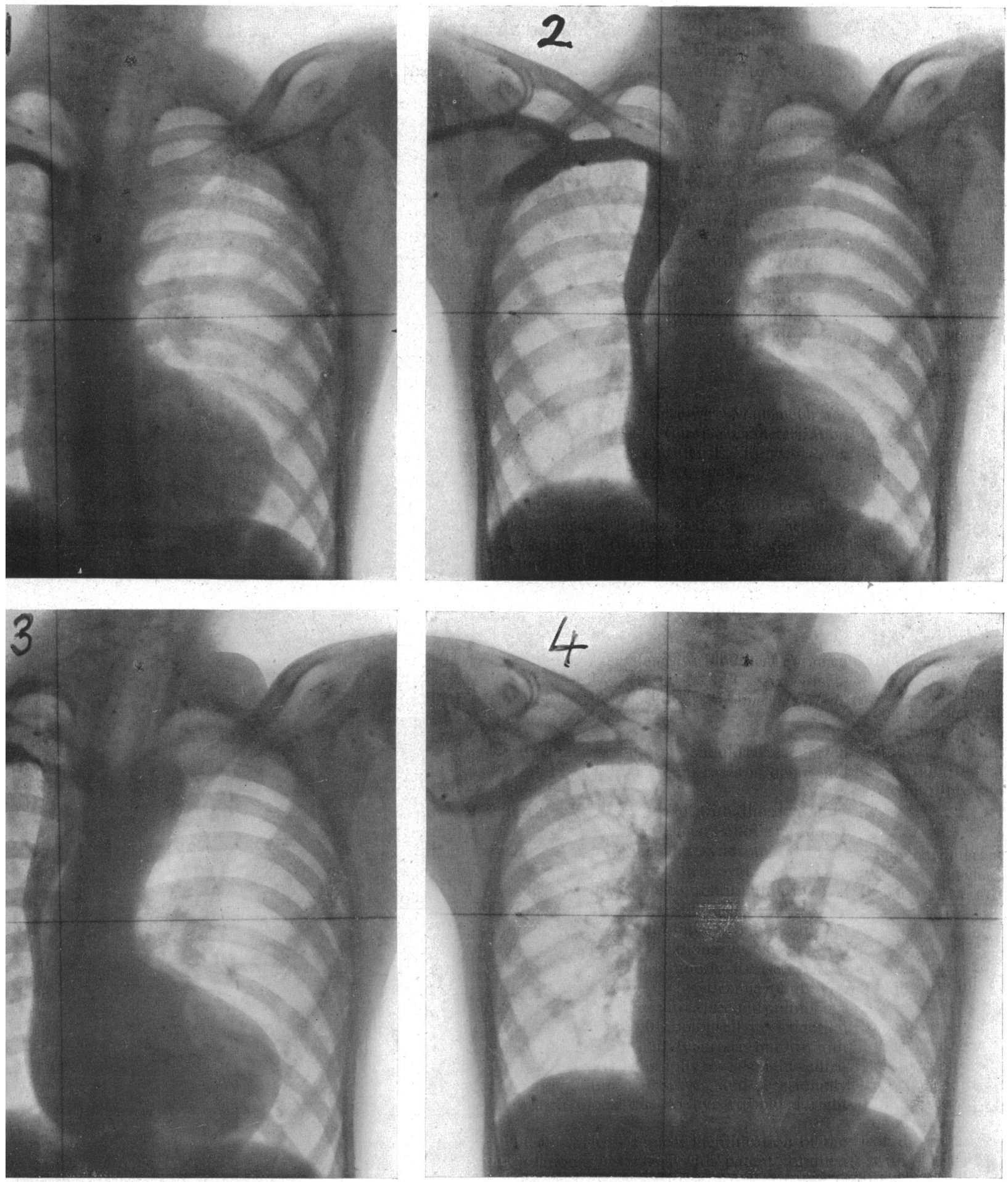

Fig. 12.-Angiocardiograms from a case of pulmonary atresia with filling of the lungs through bronchial arteries.

(1) At 1 sec., little seen except the filling of the s.v.c.

(2) At 2 sec. the diodone has passed down the rather narrowed s.v.c. to the right auricle and ventricle, and the lower part of the aorta is filling.

(3) At 3 sec. the aorta is seen much better (and the subclavian) and there is a wide branch to the right as well as the left-sided aortic arch. There is very little filling of the lungs.

(4) At 4 sec. the aorta is still well seen and the subclavian and the branch to the right are more dense. The lungs are now filling, but there is no trace of main pulmonary arteries, the right lung filling higher up and rather diffusely and the left lung filling in two or three isolated areas, where presumably there is dilatation of the bronchial arteries around the lung root. Case 0087. 
Of the 37 patients so far considered all had a right to left shunt. In Case 0021 with pulmonary atresia, the shunt was through an auricular septal defect-a type that will be seen again in the next group of tricuspid atresia, and in a modified form through a patent foramen ovale in the group that follows with pulmonary valvular stenosis.

In the other 36 cases the right to left shunt was thought to be through an over-riding aorta, presumably with a high ventricular septal defect, though some of the three just discussed (Cases 0087, 0181, and 0191) may have had a common arterial trunk.

\section{TRICUSPID ATRESIA}

The other patients not diagnosed clinically as Fallot's tetralogy, were rather varied, but several were of interest and the angiogram was often helpful in confirming or suggesting a diagnosis. Two had tricuspid atresia with a non-functioning right ventricle. This diagnosis was made on a general clinical picture like Fallot's tetralogy, but with left instead of right axis deviation in the electrocardiogram and left rather than right ventricular hypertrophy on radioscopy (Brown, 1936).

In the first (Case P057), the report of T. H. who, as usual, at the time he wrote it, had not been told the clinical diagnosis, was as follows.

The right auricle is small and the dye is seen entering the left ventricle at two seconds. At three seconds the right-sided aortic arch and the great vessels in the neck are opacified; at four seconds the abdominal aorta, and at six seconds the left renal artery are seen.

The pulmonary arteries are never well shown and begin to opacify at four seconds, and on the subsequent films the region of the right ventricle becomes a little denser.

There is a major shunt from right to left. The right ventricle filling after the left suggests that the only significant communication with this chamber is from the left ventricle.

Blood reaching the left ventricle from the right auricle without filling the right ventricle must pass through a defect of the auricular septum. Re-examination of the films shows that this is so and the upper border of the left auricle can be seen outlined at 2 seconds (Fig. 14).

This rather horizontal curve is characteristic of the upper outline of the left auricle and should
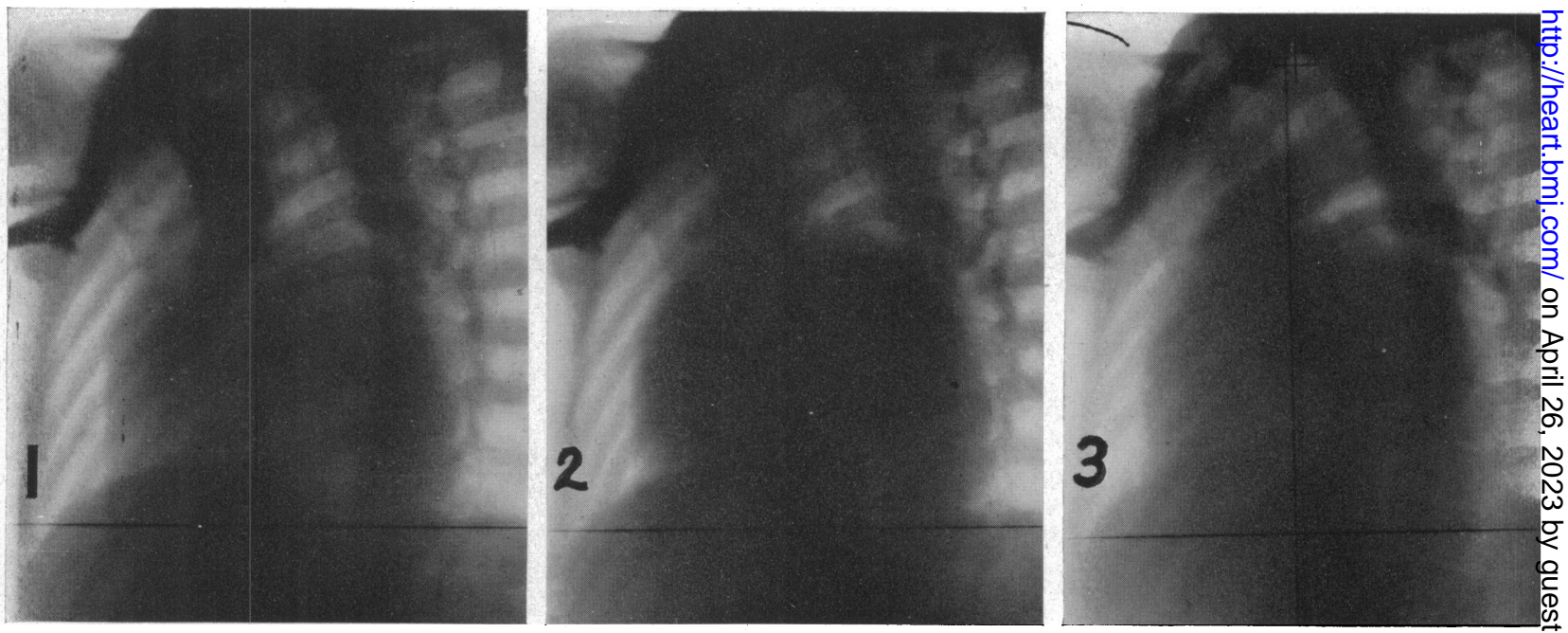

FIG. 13.-Left oblique angiocardiograms showing filling of the left auricle in tricuspid atresia.

(1) At 1 sec. most of the diodone is still in the s.v.c.

(2) At 2 sec. the right and left auricles have become dense. Looking back, after examining (3) the aorta and pulmonary artery can be seen faintly.

(3) At $3 \mathrm{sec}$. the right side of the heart is fading though the left auricle and ventricle are still dense; the aorta and the pulmonary arches are well seen passing backwards. Case 0007. 

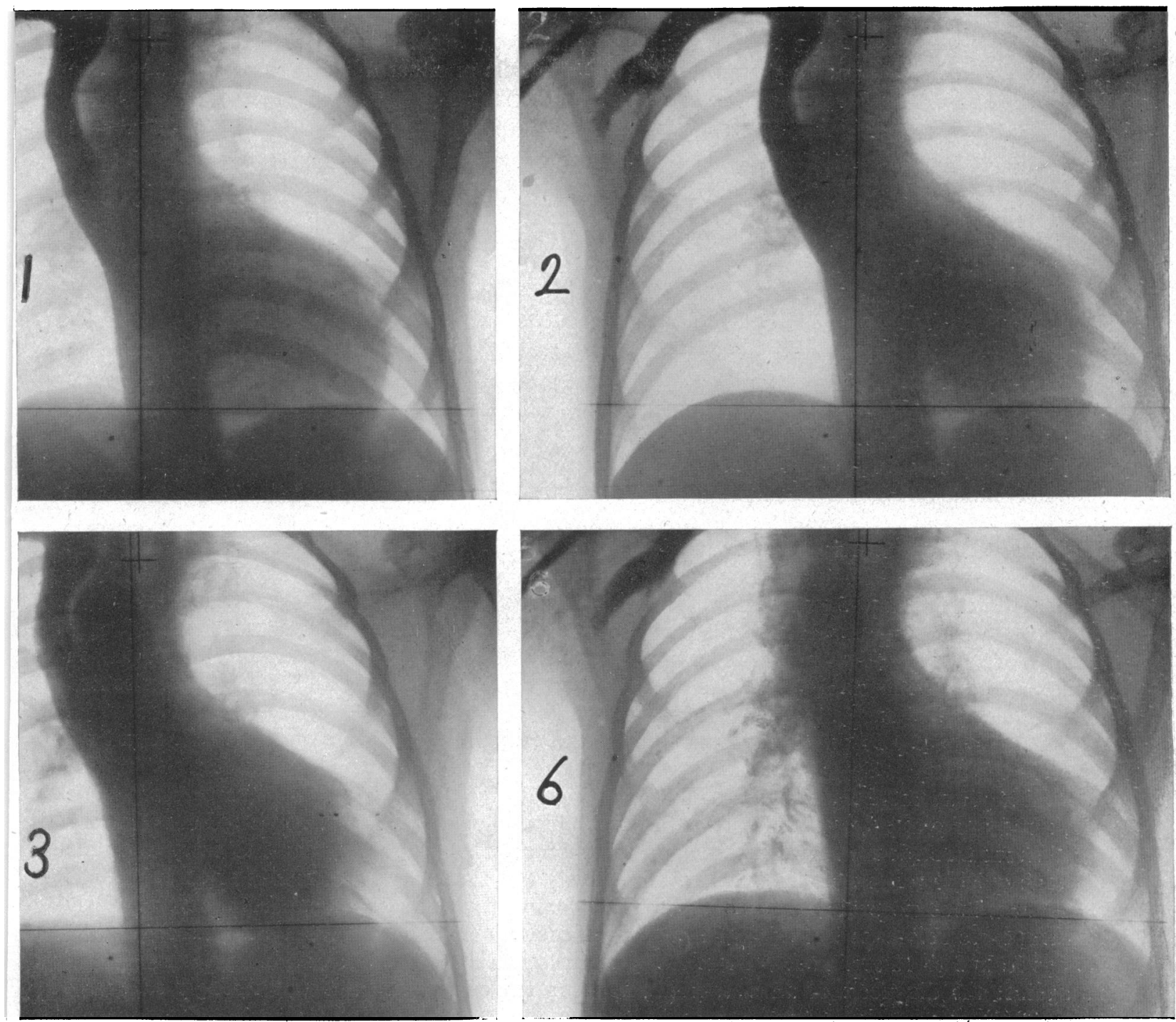

FIG. 14.-Filling of the left auricle in tricuspid atresia.

(1) At $1 \mathrm{sec}$. some diodone has reached the right auricle and passed across to the left auricle.

(2) At $2 \mathrm{sec}$. the left auricle and left ventricle are more clearly seen and a faint right-sided aortic arch is indenting the s.v.c. The triangular hollow between the spine, the diaphragm and the left ventricle, indicates an absence of any significant right ventricle.

(3) At $3 \mathrm{sec}$. the outlines are denser, especially of the aorta.

(6) At $6 \mathrm{sec}$. the same shadows can be seen, but less clearly. The subclavian has filled and the lungs are beginning to fill through the pulmonary arteries. The right ventricular window is present but fainter. Case P057.

always be looked for when a right to left shunt through the auricular septum is suspected. The clear space low down in the mid-line-which we suggest calling the right ventricular windowshows up well. It became less obvious from 6 seconds onwards as the right ventricle gradually filled from the left ventricle (Fig. 14).

In the second (Case 0007) the findings were very similar, the horizontal upper border of the left auricle being well seen at 3 seconds in the P.A. (not shown, as similar to Fig. 10) and even better in the left (II) oblique view, and the aorta in the same film, (Fig. 13), though presumably a trifle 
later. It was less obvious that the left ventricle was filled, but the translucency in the region of the right ventricle supports the view that it was the left ventricle.

The catheter could not be passed into a right ventricle in either of these cases: nor was it, in fact, passed through the auricular septal defect into the left auricle, which is more surprising. In Case 0007 the arterial blood was not much more saturated $(59 \%)$ than that in the right auricle $(53 \%)$ which might be expected, as probably the pulmonary flow was very small. In Case P057 the difference was greater ( $73 \%$ against $56 \%$ ).

Both patients benefited from a subclavian-pulmonary anastomosis, but not perhaps as much as most patients with Fallot's tetralogy, though the former has been able to leave his home and go to a government training centre for watch making.

\section{Pure Pulmonary Valvular Stenosis}

One of the commoner cyanotic conditions after-but a long way after-Fallot's tetralogy is pulmonary valvular stenosis. There were six cases where this was found and in four this was confirmed, post-mortem. Details of the clinical picture and pathological anatomy have been reported by Allanby and Campbell (1949).

Four were cyanosed, and evidence of a, right to left shunt was found by angiocardiography, though at first in one it was thought to be due to an over-riding aorta and in another it was missed and was not recognized till the subclavian artery was seen to be filled at 5 seconds. A fifth was cyanosed, and we think that he has a right to left shunt, but can see no evidence of it. The sixth was acyanotic, and there was no reason to suspect a shunt.

Sometimes in this group the shunt needs looking for more carefully than in Fallot's tetralogy. The aorta and its branches are seen so much less easily because the diodone reaches the left side much more slowly and sometimes in smaller quantity through the small patency of the foramen ovale. An over-riding aorta provides an easy direct route to the aorta and systemic arteries and is seen quickly and easily.

The evidence for a right to left shunt through the patent foramen ovale was less easily seen than in tricuspid atresia where all the blood was flowing through an auricular septal defect.

In this group there was thought to be a very high degree of stenosis (grade 5, two cases; grade 4-5, three, and grade 4, one case), preventing much blood flow to the lungs. This and the relatively small shunt through the foramen ovale and the absence of an over-riding aorta to carry away the diodone quickly mean that the heart empties slowly and that after the first two or three seconds subsequent films show very slow changes. This comment was made on the first report of nearly all these cases before we had realized its full significance-_" little change from 6 to 12 sec.", " little change from 3 to $10 \mathrm{sec}$.", and " heart still contains much dye at $14 \mathrm{sec}$.", and might have warned us against the diagnosis of an over-riding aorta in the case where this was wrongly suspected (Case 0041).

D. S. (Case H117) was first thought to have Fallot's tetralogy, but questioning her mother afterwards revealed that the history of cyanosis from birth was wrong, and that after being blue at birth no change of colour was noticed again until she was 18, after which she became progressively and severely blue, and noticed clubbing of the fingers from 25 till her death at 29 . The angiocardiographic report was a major pulmonary stenosis with no shunt: the circulation times and

Fig. 15.-Pulmonary valvular stenosis with patent foramen ovale.

(1) At $1 \mathrm{sec}$. diodone is entering the right auricle.

(3) At $3 \mathrm{sec}$. the right auricle is well filled and the left auricle and perhaps the aorta slightly; the last confirmed by the left subclavian being visible at $4 \mathrm{sec}$.

(6) At $6 \mathrm{sec}$. there is not much change, but more filling of the left ventricle and a little of the left monary artery. The delay in emptying the right auricle and ventricle confirms obstruction without any outlet such as an over-riding aorta.

(10) At 10 sec. there is still a good deal in the heart, but very little in the lungs, though the pulmo branches can be seen better now and the density in the heart is rather less. The subclavian artery is stillo seen. Case H117. 

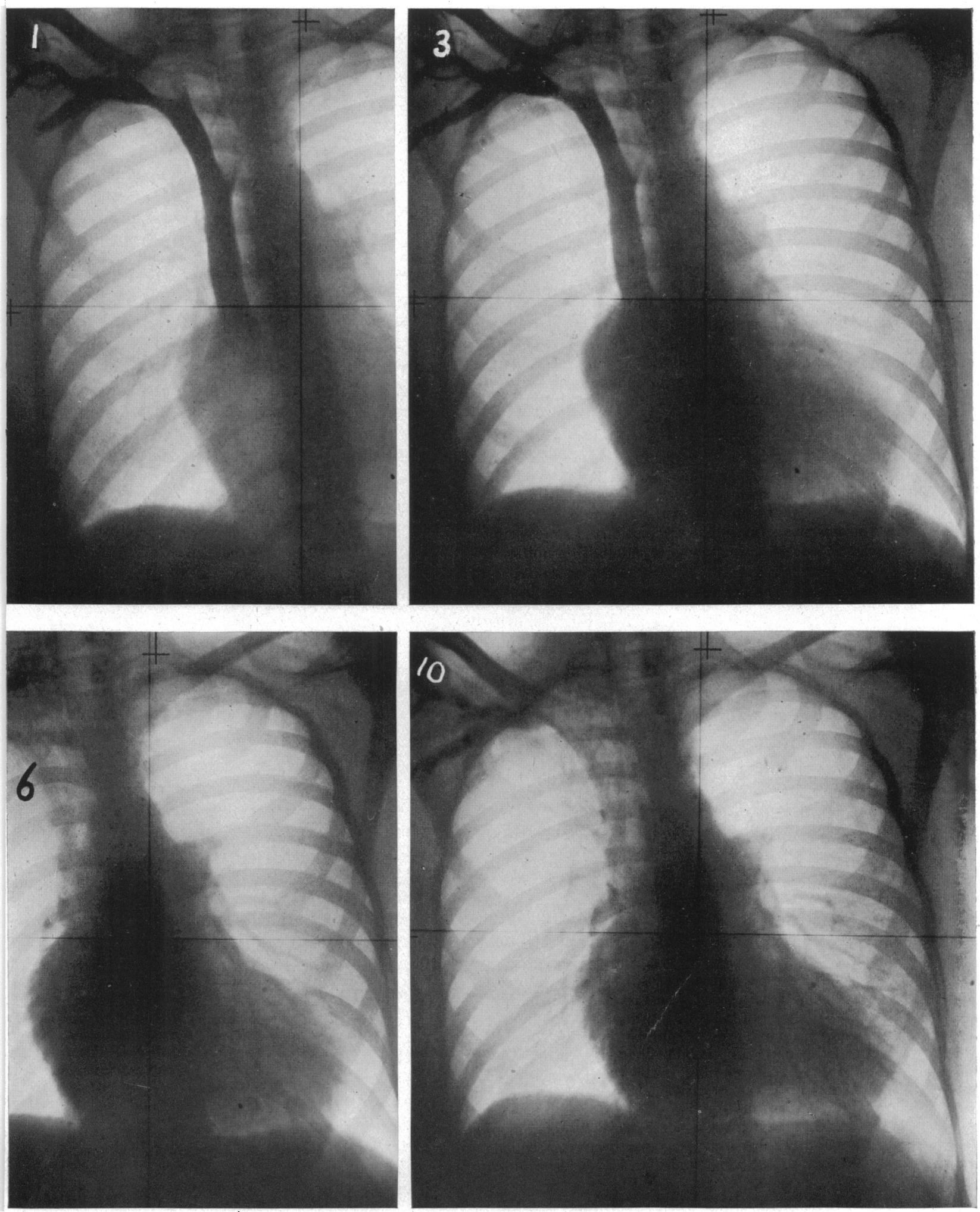

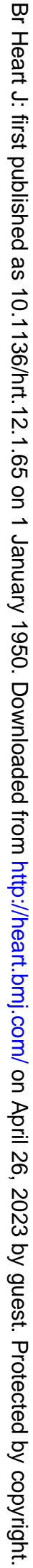


cardiac catheterization both showed much delay in the circulation and suggested high grade stenosis with only a small right to left shunt. When she died there was severe pulmonary valvular stenosis (diameter $3 \mathrm{~mm}$.) and a slit-like patent foramen ovale, $7 \times 3 \mathrm{~mm}$., partially covered by the usual valve flap.

Re-examination of the angiocardiograms showed the aorta was lightly visible at 3 and 4 seconds and the left subclavian at 5 and 6 seconds (Fig. 15), so that as in others where the aorta was not over-riding it filled more slowly because of the time taken to pass through the septal defect and the left auricle and ventricle. A faint shadow indicated the filling of the left auricle from the right auricle, but the left ventricle was poorly filled, perhaps because of ventricular systole.

R. P. (Case 0124) was similar, except that the right to left shunt was recognized at once. The right auricle was not well opacified till 4 seconds, when some diodone could already be seen out to the edge of the left ventricle. The aorta and the pulmonary arteries were both seen at 6 seconds . Here too, the diagnosis was confirmed post-mortem, and as the foramen ovale admitted the tip of one finger, filling of the left side might have been expected earlier. On the angiocardiogram alone it was not possible to say that the shunt was through a defect in the auricular septum, but this could probably have been shown in the left (II) oblique position.

G. B. (Case 0041) had the main features of Fallot's tetralogy, but cyanosis was not noticed till she was four, and she did not squat. On screening she showed a very prominent pulmonary artery and some apparent enlargement of the left ventricle as well as of the right, though the latter was greater: on these findings the provisional diagnosis was Eisenmenger's complex.

A year later the heart was larger (c.t.r. 63 instead of 57) and the prominence of the pulmonary artery certainly no less; we thought, with increasing experience of this type that she had pulmonary valvular stenosis with a dilated pulmonary artery, and a large patent foramen ovale, for the cyanosis was gross.

Angiocardiography showed extreme pulmonary stenosis and apparently an over-riding aorta, but did not look like Fallot's tetralogy in that the heart as a whole was still dense at 8 seconds, which should have made us more doubtful about an over-riding aorta that would have taken away the diodone more quickly (Fig. 16). No evidence of the right to left shunt through an auricular septal defect, as with other similar cases, was seen.

Cardiac catheterization showed very low oxygen saturation, and very high pressure in the right ventricle; the pulmonary artery was not entered. The diagnosis was pulmonary valvular stenosis with a patent foramen ovale, but it remained somewhat doubtful, as Fallot's tetralogy with a high grade of pulmonary valvular stenosis seemed an alternative.

At operation, valvular stenosis was confirmed, but the heart stopped before this could be relieved. Post-mortem, the righ to left shunt was through a patent foramen ovale.

The fourth (Case P076) is still alive, so the diagnosis is not proved. There had been cyanosis from birth without much polycythæmia or clubbing of the fingers, and right bundle branch block was thought to favour auricular septal defect and radioscopy favoured pulmonary stenosis. The angiocardiogram suggested a major pulmonary stenosis and a moderate right to left shunt, probably through a patent foramen ovale; there was little change in the shadows from 3 to $10 \mathrm{sec}$. Catheterization supported these findings.

In the other two cases there was no evidence of a right to left shunt. The first (Case OA11) provided a good example of the normal U-shaped filling of the heart and poor filling of the lungs, thus supporting the diagnosis of pulmonary valvular stenosis with no evidence of a shunt. We

- cannot think that this diagnosis was correct, as he had been cyanosed from nine months old, and increasingly so. Cardiac catheterization supported the view that he had pulmonary stenosis and also a right to left shunt.

The second (Case P212) had a very large right auricle (and indeed a very large heart), and the filling showed the normal U-shaped curve of the right side of the heart (Fig. 17). The pulmonary stenosis was thought to be of the highest grade (the diameter of the pulmonary orifice was $3 \mathrm{~mm}$., post-mortem), and the aorta and its branches were not visualized. She had a very large pulsating liver and a diagnosis of tricuspid regurgitation was made. There was a fan-shaped shadow passing from the angle of the auricle and the inferior vena cava out into the liver which was, we think, 
produced by tricuspid regurgitation, but it can hardly be seen in Fig. 17. All these points made in the diagnosis were confirmed post-mortem.

These last two cases are the first good demonstration of the normal U-shaped filling of the right side of the heart, because in most cases of Fallot's tetralogy the C-shaped over-riding aorta quickly fills in the hollow of the $U$, and when the opaque substance passes from the right to the left auricle this also obscures the hollow.

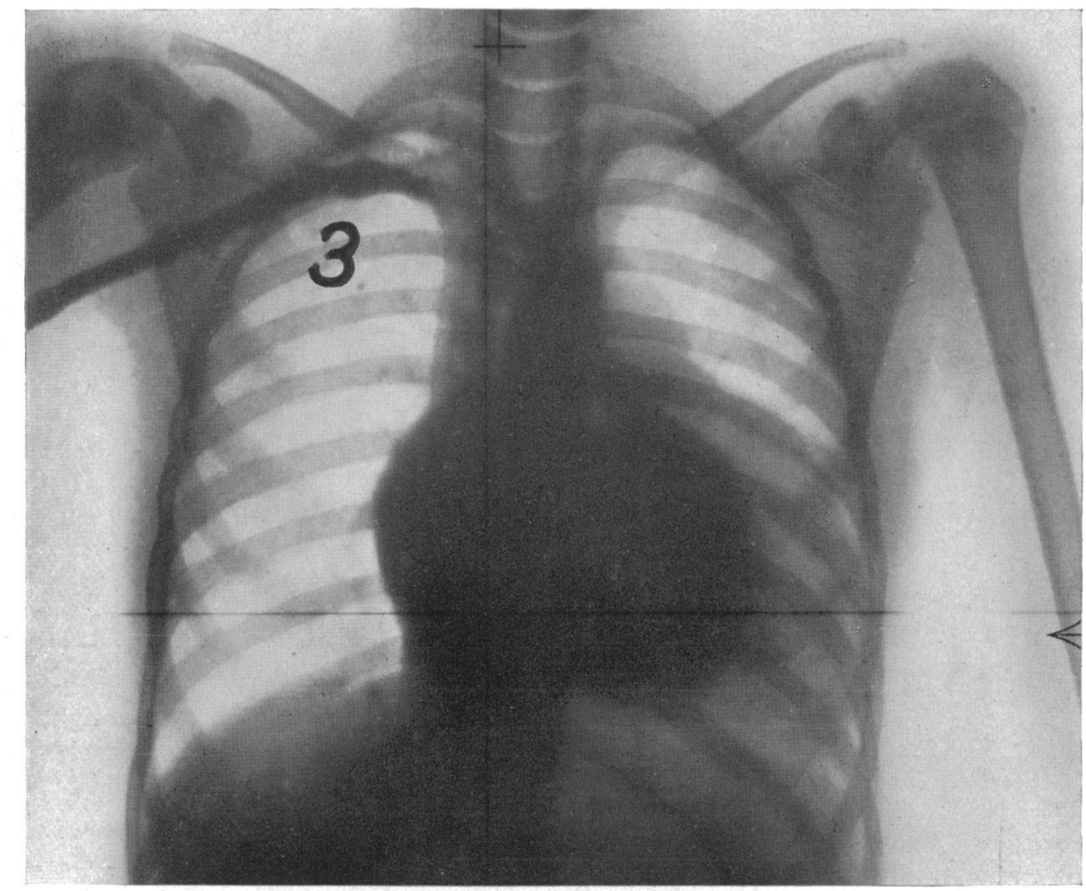

FIG. 16.-Pulmonary valvular stenosis with patent foramen ovale.

At $3 \mathrm{sec}$. a large right auricle and the right ventricle are well seen, but no pulmonary artery. The aorta and its branches have filled well-in fact, from the left ventricle and left auricle, though there was difficulty in excluding an over-riding aorta; the general delay in the emptying of the heart was one of the main arguments against this. Case 0041 .

A seventh patient (Case 0368) was originally included in this group as the physical signs and the absence of cyanosis suggested the diagnosis of pure pulmonary stenosis. The original report of the angiocardiogram suggested moderate pulmonary stenosis, and that the aorta opacified faintly at three and more at four seconds, indicating a moderate right to left shunt or over-riding aorta.

It seemed doubtful if this could be correct as normal circulation times supported the clinical view of no significant right to left shunt. When a final analysis showed he was the only case where a shunt had been found without clinical cyanosis, further re-examination of the films showed that there was no evidence of a shunt, the change in the aorta being doubtful and nothing being certain till the subclavian artery filled at 7 and 8 seconds, which might have been normal filling through the lungs as the pulmonary stenosis was not severe. Probably, the mistake arose from accepting an aorta that could just be seen for one that had become opacified but apart from anything else this should not have happened, because of its distance from the left border of the superior vena cava, which is generally indented by the aorta and shows where the latter will be before it becomes opaque. We mention this mistake because in any doubtful aorta the filling of the branches should always be looked for. 


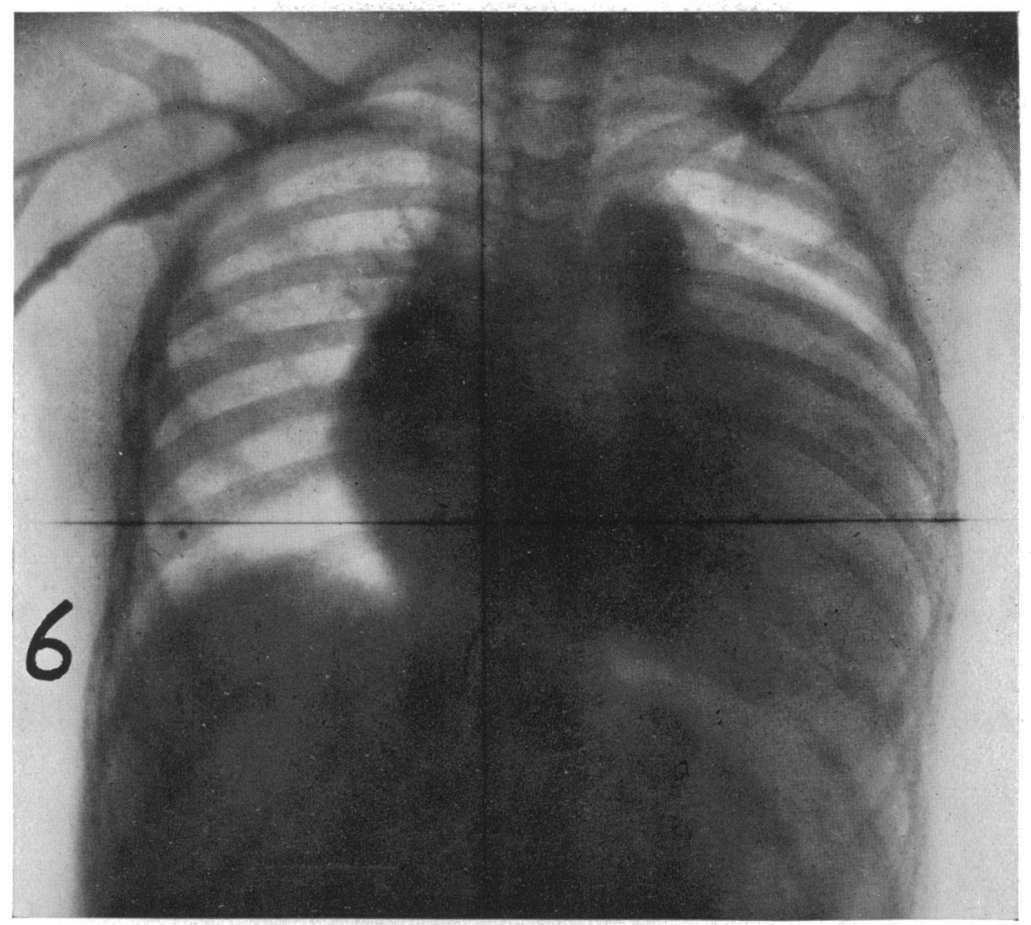

FIG. 17.-Pulmonary valvular stenosis with closed septa.

A large right auricle and large right ventricle were filled, without any signs of a right to left shunt or significant filling of the lungs at $2 \mathrm{sec}$. (not shown).

At $6 \mathrm{sec}$. the U-shape of the right side of the heart can be seen with the densest shadow at the upper part of the left limb of the $U$ showing the dilated pulmonary artery above the valvular stenosis. There is still very little filling of the lungs and no signs of any right to left shunt. The film at $12 \mathrm{sec}$. (not shown) still showed a good deal of diodone on the right side and the pulmonary artery a little more filled, but the aorta was not visible. Case P212.

\section{Transposition of the Aorta and Pulmonary Artery}

Two cases with this clinical diagnosis are included. Angiocardiography suggested the transposition was complete in one and not so complete in the other.

The former, Case 0052, was 9 years old and was only able to walk a few yards. He had been moderately cyanosed from birth, with gross clubbing of the fingers and polycythæmia, the hæmoglobin being 148 per cent. Triple rhythm combined with a loud but variable booming second sound in the pulmonary area were the most noticeable physical signs.

Radioscopy showed a slight increase in the size of the heart, mainly of the right ventricle, but a great increase in both pulmonary arteries and their branches, which could be easily seen spreading through the lungs with expansile pulsation seen nearly out to the periphery. It was on these findings that the diagnosis was made.

The film at 2 seconds shows the normal U-shaped curve of the right side of the heart and the aorta filling freely from the right ventricle, exactly in the position where the pulmonary artery should rise (Fig. 18). From 3 seconds onwards diodone is seen in the pulmonary arteries, though the lower part of the left ventricle is not seen till 4 seconds, having presumably filled through a ventricular septal defect.

The cardiac catheter passed easily from the right ventricle to the aorta, right subclavian, and common carotid. There seemed to be a left to right shunt, possibly as well as a right to left shunt, through a high ventricular septal defect, as the oxygen saturation rose from 40 per cent in the right 


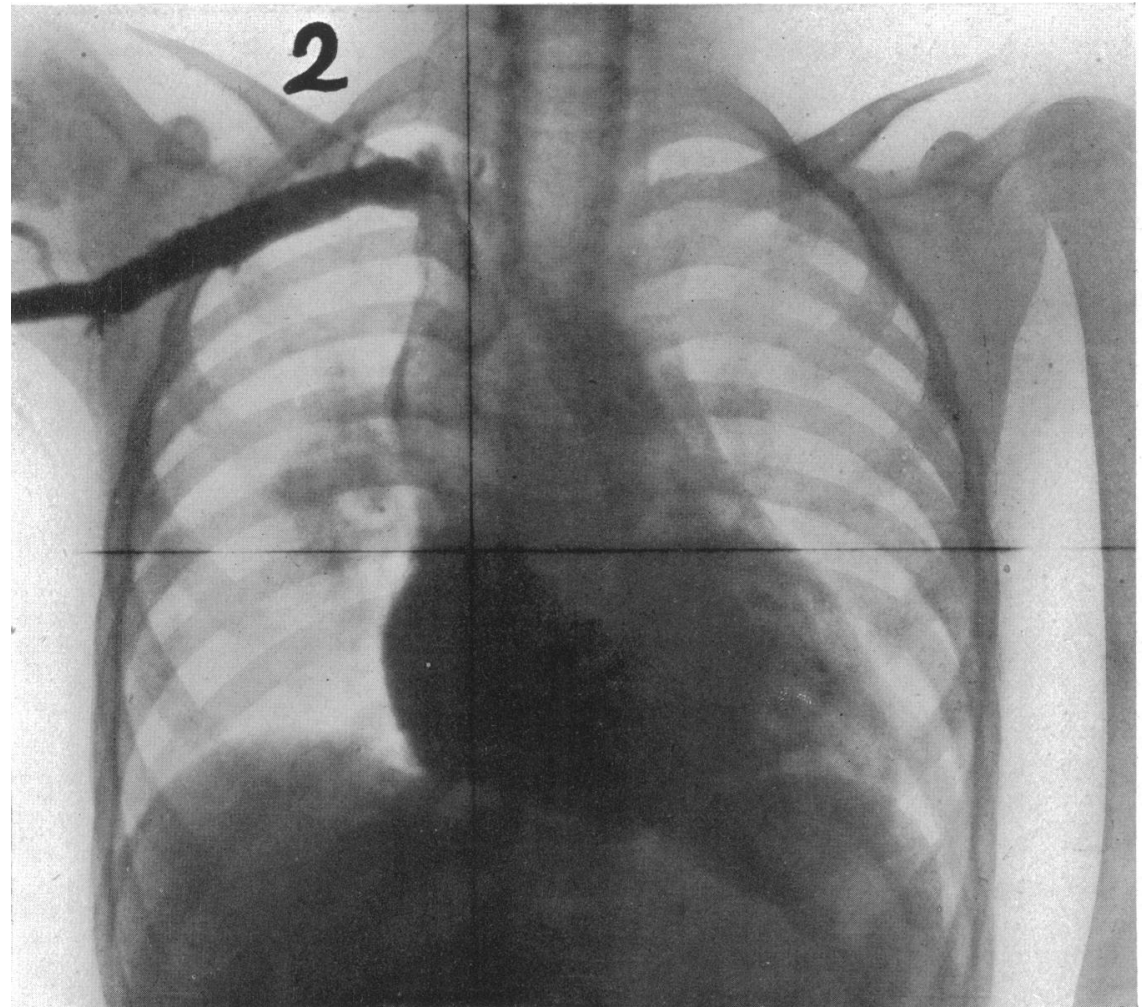

FIG. 18.-Complete transposition of the aorta and pulmonary artery.

(1) At $1 \mathrm{sec}$. there is diodone in the right auricle. There is an unusual indentation of the left side of the s.v.c., which later films show to be due to the dilated pulmonary artery instead of, as usual, the aorta. The P.A. is already visible in this first film because it was so dilated, but did not show more blood than in its normal resting condition.

(2) The film at 2 sec. (shown above and less reduced) shows the U-shape of the right side of the heart, with the aorta arising from this, as a direct continuation of the right ventricular outflow tract; the innominate and carotid arteries are well seen. There is no increase yet in the pulmonary shadows.

(3) At $3 \mathrm{sec}$. diodone has entered the left ventricle, probably through a ventricular septal defect, because of the clear space between the limbs of the $U$ in the previous film. The lungs are now beginning to fill, and the aorta and its branches are still equally dense. Case 0052.
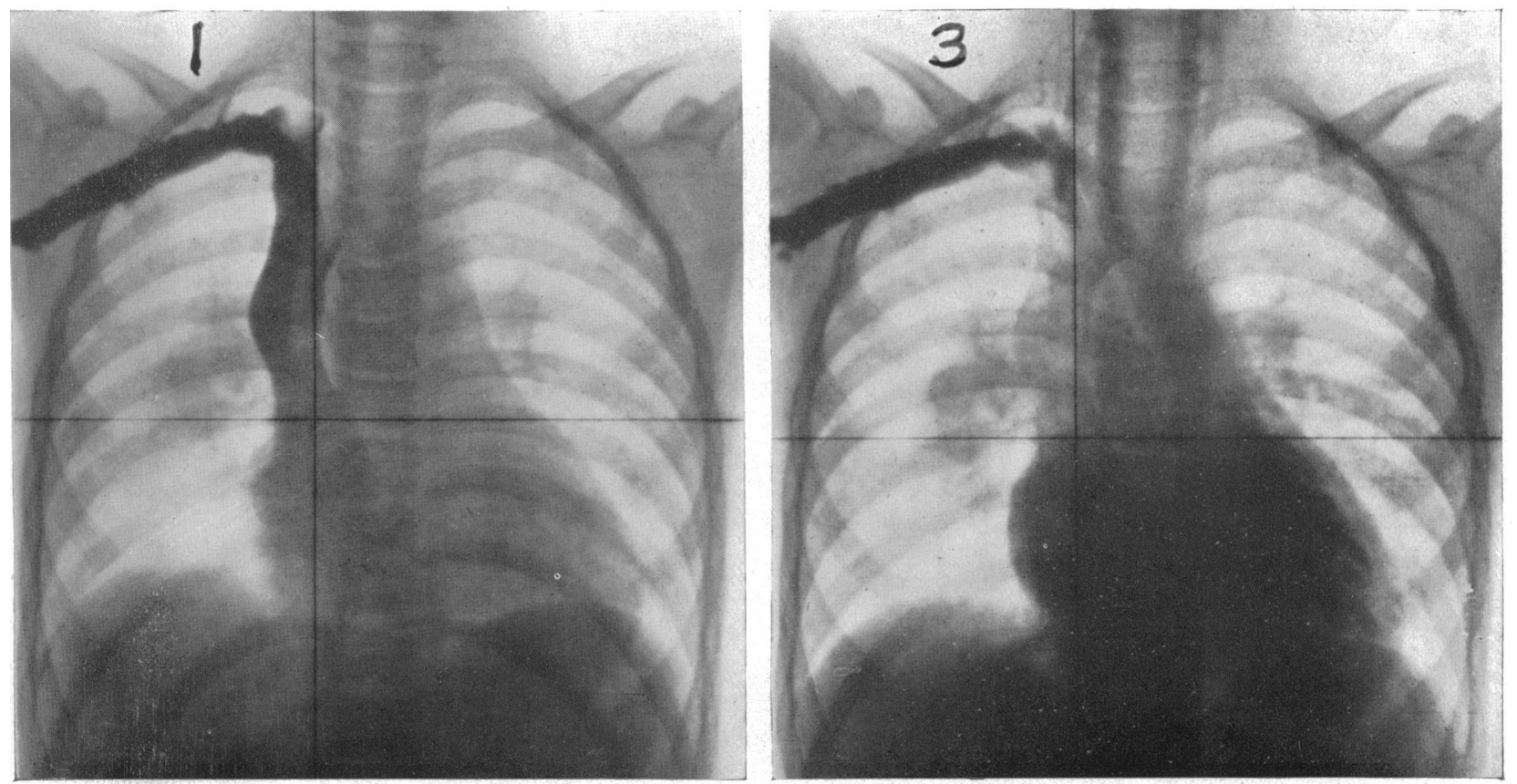

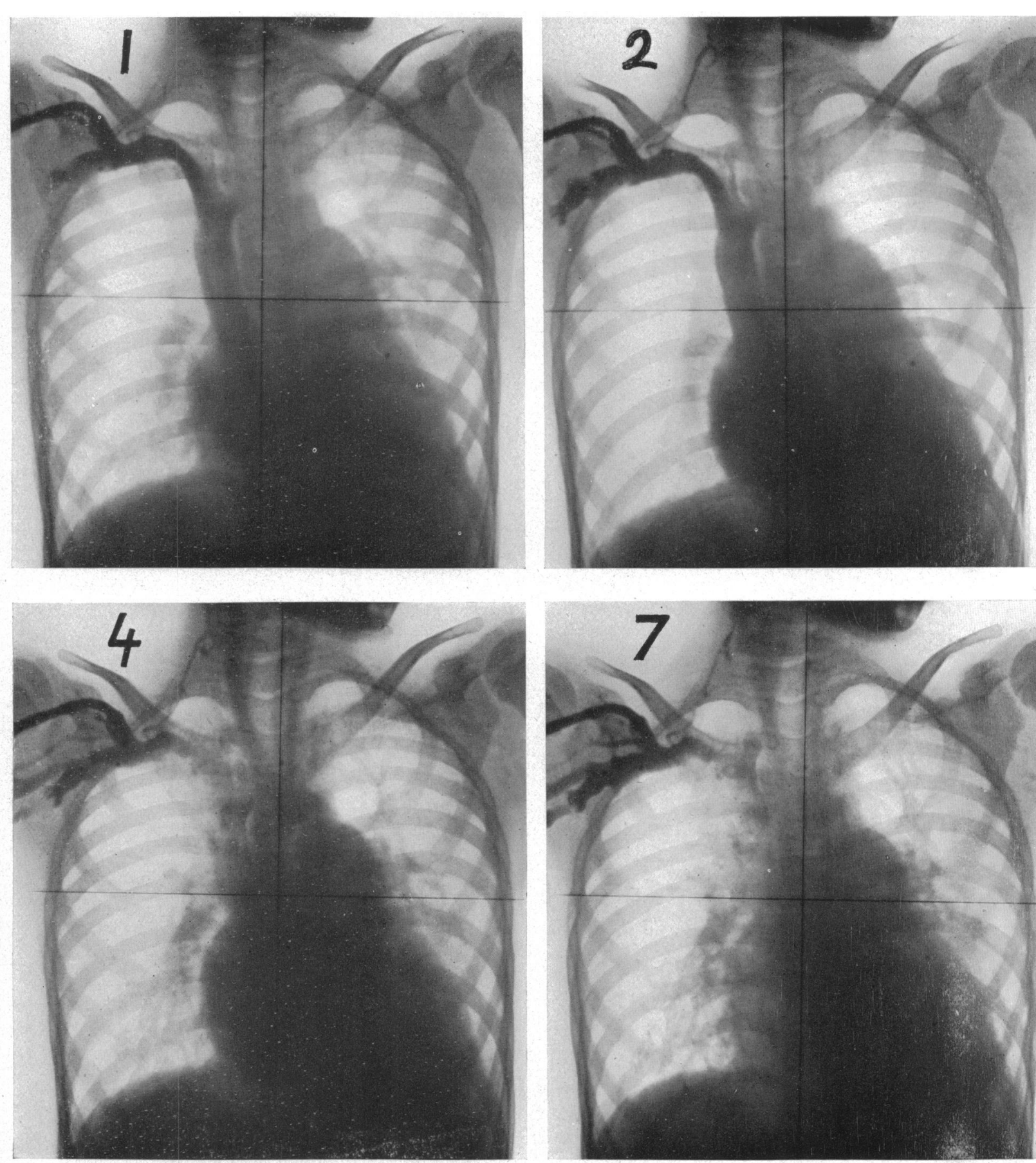

Fig. 19.-Partial transposition of the aorta and pulmonary artery.

(1) At $1 \mathrm{sec}$. there is some filling of the right auricle and ventricle.

(2) At $2 \mathrm{sec}$. there is more filling of the right ventricle and the aortic arch is already seen, though it appears more in the over-riding position than completely transposed, as it was in Fig. 18.

(4) At $4 \mathrm{sec}$. the aortic arch and its branches show clearly, and below this some filling of the pulmonary artery and its right branch. The left ventricle now seems well filled and the pulmonary artery may have filled entirely from this, though some degree of over-riding is difficult to exclude.

(7) At $7 \mathrm{sec}$. the shadow of the right auricle and the aorta (and probably the right ventricle) are fading, but there is no decrease in the density of the left ventricle or pulmcnary artery and its branches. Case 0076. 
auricle to $49 \cdot 6$ per cent in the right ventricle near the outflow tract, and to 52.8 per cent in the aorta. The pulmonary artery was not entered, which is not surprising if it arose from the left ventricle.

The diagnosis was complete transposition of the aorta and pulmonary artery with a ventricular septal defect, and possibly with an auricular septal defect also, though no direct evidence of this was obtained.

The second (Case 0076) had moderate cyanosis, and polycythæmia, the hæmoglobin being 122-130 per cent. He could sometimes walk half a mile. The heart was slightly enlarged (c.t.r., $11 / 20 \mathrm{~cm}$.) and the pulmonary arteries were greatly dilated, with pulsation well seen out to the periphery.

On angiocardiography the aorta was.seen at 2 seconds and better at 3 seconds (Fig. 19), but it was not very well filled and seemed to arise like an over-riding aorta and not wholly from the right ventricle as in the previous case. The pulmonary arteries were seen at the same time as the aorta, but though they were dilated the lungs filled slowly. If the pulmonary artery arises from the right ventricle it is difficult to reconcile this poor filling and the high degree of pulsation on screening, but if it arises from the left ventricle it would be expected, and there would be only slight early filling, either because the pulmonary artery over-rides the right ventricle slightly or because blood has passed from the right to the left ventricle through a septal defect.

Cardiac catheterization supported the clinical diagnosis and the final diagnosis was partial transposition of both aorta and pulmonary artery.

The first case is almost exactly the same as the one reported by Goodwin, Steiner, and Wayne (1949) and the teleradiograms are very similar (their Fig. 2 and Campbell, 1948, Fig. 12). Comparing this film with cardiac contours that Taussig thought characteristic of transposition they pointed out rightly that there were striking differences, especially in the broader pedicle. We think this contour most suggestive of transposition with a septal defect.

\section{EISENMENGER'S COMPLEX}

The remaining two were thought to have Eisenmenger's complex. A girl, aged 23, (Case 0261) had been fairly deeply cyanosed since she was three years old. She had not been able to play games at school because of dyspnœa, though she had been able to walk a mile at her own pace until the last two years. She had not squatted. Her colour was exceptionally high, the hæmoglobin being 160 per cent, and her fingers showed a moderate degree of clubbing.

She had a rough systolic murmur and thrill in the pulmonary area without any diastolic murmur, and the pulmonary sound was at the upper limits of normal. There was right ventricular preponderance in the electrocardiogram, confirmed by $\mathrm{V}$ leads, and also a very large pointed $\mathrm{P}$ in lead II.

Her heart was enlarged (c.t.r. 59, 11.9/20 c.m.). On screening the right ventricle was considerably enlarged in the oblique view, there was a large dilated pulmonary artery, enough to call aneurysmal, and pulsation could be seen out into the branches. The aortic arch was right-sided.

Cardiac catheterization helped to confirm this diagnosis. The pressure in the right ventricle was $95 / 5$ and in the pulmonary artery $95 / 55 \mathrm{~mm}$. $\mathrm{Hg}$. against a systemic pressure of $130 / 80$. The $\mathrm{O}_{2}$ saturation was 77 per cent in the femoral artery, 62 per cent in the right ventricle, and 74 per cent in the pulmonary artery, suggesting a left to right shunt through the high ventricular septal defect, as there was no evidence of a patent ductus. The pulmonary and systemic blood flows were about the same and 70 per cent of the average normal, suggesting that the right to left and the left to right shunts were about equal.

If this diagnosis is right, and catheterization seems to prove it, this is one of the cases where the angiocardiogram is least helpful (Fig. 20). The aorta was never well defined and was missed at first, but could be seen faintly at 3 and 4 seconds and dye was seen in the subclavian from 6 seconds onwards, which is too early for its arrival by the normal circuit as the lungs did not 

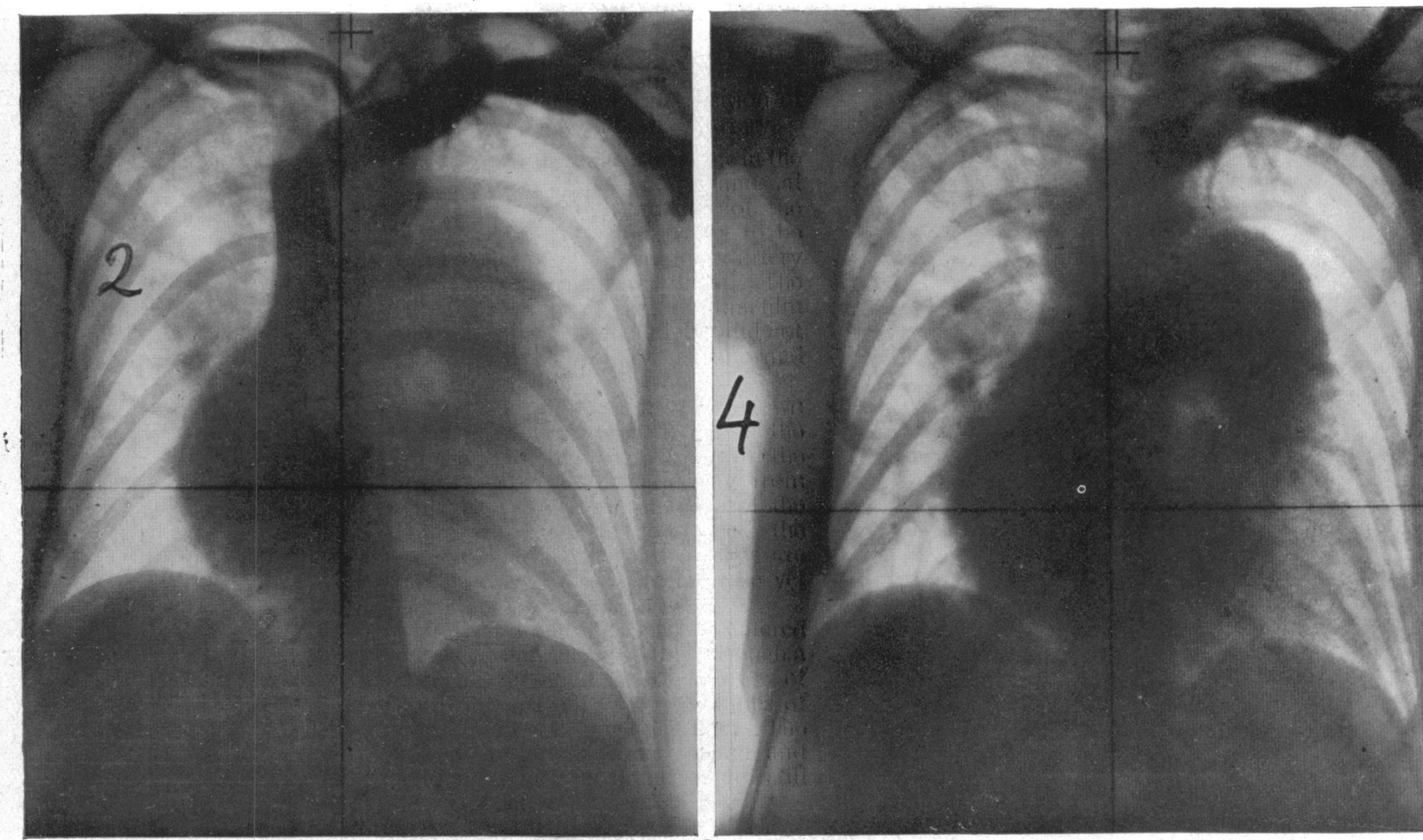

FIG. 20.-A large dilated pulmonary artery in Eisenmenger's complex.

(2) At 2 sec. diodone has reached the right auricle, but probably not much further, though the pulmonary artery is visible.

(4) At 4 sec. the large dilated pulmonary artery has filled completely and several branches in the lungs can be clearly seen. A small aortic knuckle is visible above this shadow, but considering her deep cyanosis the right to left shunt was not as great as expected. Case 0261.

fill quickly or well. There was, therefore, evidence of only a slight right to left shunt in spite-of her low arterial saturation.

Nor were the findings in the pulmonary circulation as expected. The pulmonary artery, especially on the left side (but probably the main trunk), was grossly dilated and filled at 3 seconds. But it remained filled throughout and did not make the lungs much denser except in the right upper lobe, so that she was thought to have some diminution of the blood flow to the lungs (catheterization suggested 70 per cent of normal blood flow). It looks as if a dilated pulmonary artery and increased density of the lungs may sometimes be associated with more blood in the lungs rather than with increased flow.

The other (Case H126) had the main features of Fallot's tetralogy of moderate severity, but did not squat. The size of the heart (c.t.r. 66), some enlargement of the left ventricle as well as of the right on screening, and some possible left axis deviation in the standard leads, made us think tricuspid atresia possible, but the chest leads confirmed right ventricular preponderance. The inverted $\mathrm{T}$ in lead $\mathrm{I}$ might indicate an abnormal coronary artery arising from the pulmonary artery. The abnormal superior vena cava is shown in Fig. $2 \mathrm{~B}$.

The only certain features on angiocardiography were that she had a fairly large right to left shunt and that pulmonary stenosis was absent or trivial. It seems, therefore, that she had Eisenmenger's complex, or Fallot's tetralogy with relatively little stenosis and some complication, such as a single ventricle, producing the enlargement that seemed to affect both ventricles. 


\section{AbNoRMalities of THE VeINS}

Apart from the main findings, several venous abnormalities of interest have been revealed by angiocardiography. In one patient there was a left superior vena cava; a smaller vessel could also be seen on the right, but seemed to taper off and it was doubtful if it entered the heart normally. Outside the left vena cava was another shadow that did not fill, so possibly the jugular vein ran down by the side of it, not communicating with it until almost in the heart (Fig. 2B).

In another diodone entered the right auricle by a superior vena cava that lay on the left (Fig. 10). Catheterization had already shown that the auricle could be entered through a right vena cava, but little dye crossed over to the other side, so it looked as if both these entered the auricle separately. Looking back at the straight X-ray film both superior venæ cavæ could be seen.

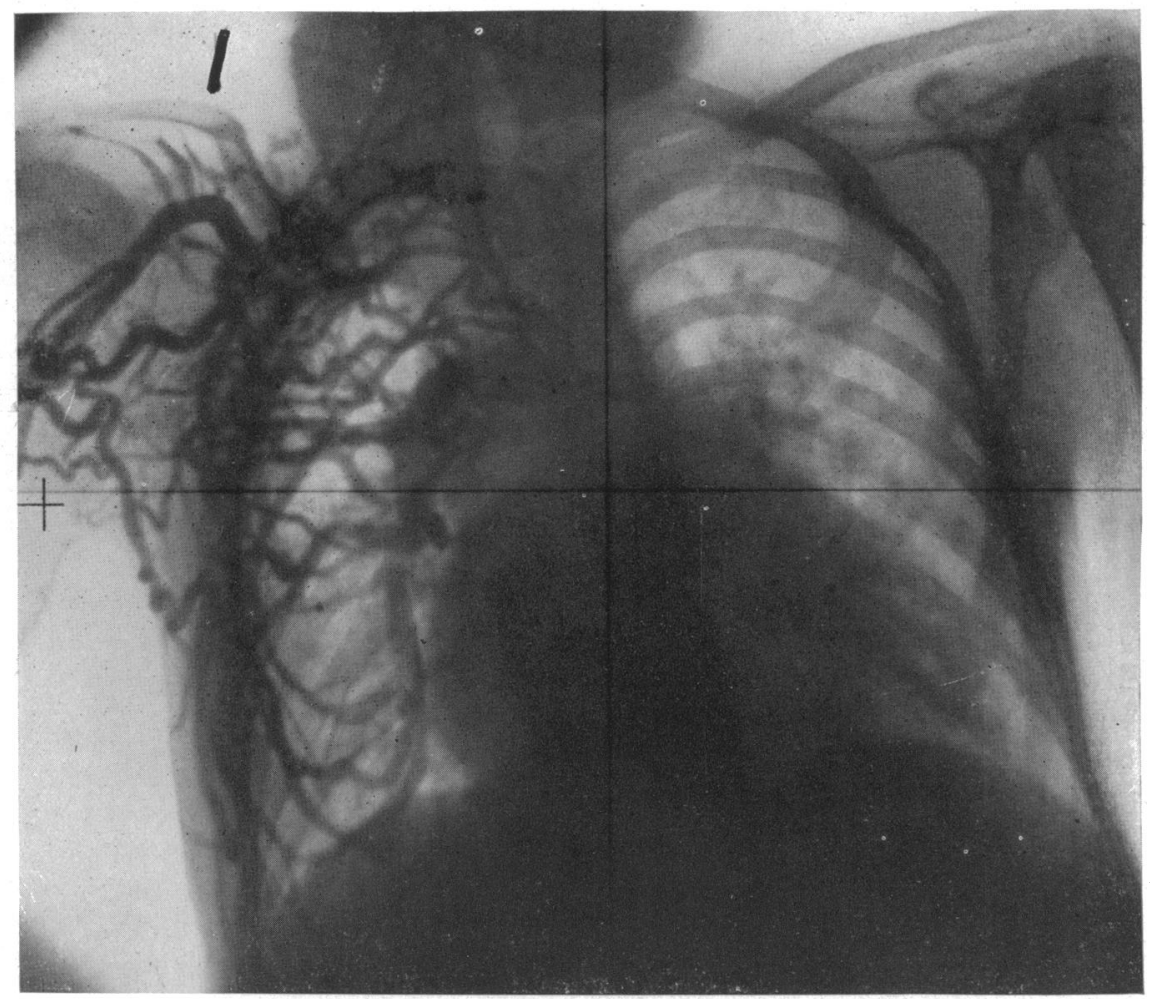

Fig. 21.-A complicated venous anastomosis in a patient who was thought to have arterio-venous aneurysms in various parts of the body. The film at $1 \mathrm{sec}$. shows this over the right chest well and no s.v.c. is really seen. Drainage seems to be to the azygos veins and the right side of the heart fills slowly. The speed with which the diodone is removed suggests a rapid blood flow.

In one cyanotic patient with a diagnosis of multiple arterio-venous aneurysms, not included in this series, there was a remarkable picture of anastomoses in the chest wall and no superior vena cava was clearly seen, so that diodone seemed to be reaching the heart through some anastomosis of the intercostal with the azygos veins (Fig. 21).

In another there was a large pulmonary artery on one side with obstruction on the other, shown post-mortem to be due to thrombosis in the pulmonary artery.

\section{SUMmaRY AND CONClusions}

Angiocardiograms have been taken with a roll film camera at one second intervals by a method designed by Hills (1948). The small films cannot at present show the detail of a full-size film, 
but facilitate serial comparison-a most important point in the diagnosis of congenital heart disease.

In severe cases of cyanotic heart disease angiocardiography is not without risk, and we have had two deaths in 70 cases. For children an anæsthetic is needed and whatever choice is made it should be given by an experienced anæsthetist with a liberal excess of oxygen. The first 15 minutes after angiocardiography is a dangerous period, so oxygen should be continued for at least 20 minutes even when the patient is safely back in bed.

The first film of the series will often show some venous backflow due to a temporary rise of venous pressure, often into the internal jugular vein or the inferior vena cava. This rise of pressure must be remembered, but rarely persists after two seconds, and does not seem to be the cause of the right to left shunt in any of this series.

In the first 50 cases of cyanotic congenital heart disease where angiocardiography has been carried out, 31 were thought to have Fallot's tetralogy. The volume of the right to left shunt is estimated mainly by the proportion of diodone in the aorta, which is seen as early as two or three seconds after the injection. The filling of the subclavian and other systemic arteries gives further evidence of the amount taking this route.

The pulmonary arteries show some filling at two seconds, but the degree of stenosis should not be assessed on a time basis alone. If there is a normal blood flow through the lungs their general density will increase to a maximum in 2 or 3 seconds; if there is pulmonary stenosis, in 4 to 6 seconds, or less if a grossly over-riding aorta carries away most of the diodone. The changing density of the lung fields is a better guide than the time of arrival or the degree of filling of the main arteries, which may be dilated.

In all these 31 cases there was a right to left shunt and in all but one it was large and easily seen. In 25, angiocardiography showed moderate or severe pulmonary stenosis: in 6 it seemed slighter, and this led to some doubt about their suitability for the Blalock-Taussig operation, which was, however, as successful as in the others.

One case resembled Fallot's tetralogy in some but not in all features, and proved post-mortem to have pulmonary atresia.

There were 5 others where the picture was of Fallot's tetralogy with the addition of signs of patent ductus arteriosus. In one, this diagnosis was supported by operation. In another, necropsy showed that there was, in fact, complete pulmonary atresia with a patent ductus, and some at least of the others were thought to have pulmonary atresia, or perhaps in one case a common arterial trunk, with the pulmonary blood supply through bronchial arteries.

There were 2 cases where the clinical diagnosis was tricuspid atresia with a non-functioning right ventricle, and in these there was confirmatory evidence, the aorta filling a little later and apparently from the right auricle through an auricular septal defect to the left auricle and so to the left ventricle and aorta.

There were 7 cases where the clinical diagnosis was pulmonary valvular stenosis without a ventricular septal defect, but sometimes with a patent foramen ovale. In three of these there was no evidence of any shunt (though in one we think it must have been present) and in one, who was acyanotic, the absence of a septal defect was confirmed post-mortem. In the other four there was thought to be a right to left shunt through a patent foramen ovale, and in three of these it was confirmed post-mortem.

In 2 the diagnosis was thought to be Eisenmenger's complex: in one of these there was good evidence to support this on cardiac catheterization, but less decisive evidence from angiocardiography.

In the last two cases the clinical diagnosis was transposition of the aorta and pulmonary artery with septal defect; supporting evidence was found from angiocardiography and cardiac catheterization though in the second it was not conclusive and the transposition was probably partial.

Of these 50 cases, 48 were cyanotic and all these, except one, had evidence of a right to left shunt, though in three it was slight and not easily seen. In the one exception, who had been moderately 
cyanosed since he was nine months old, catheterization suggested a right to left shunt, and we think the angiocardiogram failed to demonstrate it.

Of the two acyanotic cases, neither had evidence of a right to left shunt, and in one the absence of any septal defect was confirmed post-mortem. A right to left shunt was, therefore, present in 47 cases. In 36 it was thought to be due to an over-riding aorta, probably with a high ventricular septal defect, and in one other this was difficult to exclude. In 4 it was not certain where the right to left shunt was.

In the remaining 7 it was through an opening in the auricular septum. In 3 of these, two with tricuspid atresia and one with pulmonary atresia, it was through a true auricular septal defect (one proved post-mortem): the upper border of the left auricle was generally seen very clearly. In 4 with pulmonary valvular stenosis it was through a patent foramen ovale (three proved postmortem), and in these the evidence of the right to left shunt was often less well seen. This might be expected when only a small proportion of the blood is passing through a small patency of the foramen ovale, instead of the whole of it through an auricular septal defect because there is no direct way from the right auricle to the right ventricle.

Unsuspected abnormalities, such as a double superior vena cava were sometimes found.

We have discussed the angiocardiograms mainly from the point of view of diagnosis, but in cases for operation the detailed picture of the anatomy of the arteries is of value to the surgeon in deciding if and how a subclavian-pulmonary anastomosis should be attempted, and may help in deciding if a Blalock-Taussig operation or Brock's direct attack on the obstruction is indicated.

We are greatly indebted to Dr. Ian Hill for giving most of the injections for these angiocardiograms and to Dr. E. H. Rink for giving many of the anæsthetics and for his help in the section about this. We should like to thank our fellow members of the Peacock Club for many discussions on these films from time to time, and especially Mr. R. C. Brock. We should also like to thank Dr. Frances Gardner for her useful suggestions, Dr. Charles. Baker for the use of some of his cases, and Dr. Holling and Dr. Zak for their results of cardiac catheterization.

The Photographic Department, Guy's Hospital have helped us with the illustrations.

\section{REFERENCES}

Allanby, K. D. and Campbell, M. (1949). Guy's Hosp. Rep., 98, 18.

, Brinton, W. D., Campbell, M., and Gardner, F. (1950). Ibid. (In the press).

Baker, C. G., Brock, R. C., Campbell, M. and Suzman, S. (1949). Brit. Heart. J., 11, 170.

Brocklebank, J. A. (1948). Brit. J. Radiol., 21, 393.

Brown, J. W. (1936). Arch. Dis. Child., 11, 275.

Campbell, M. (1948). Guy's Hosp. Rep., 97, 1.

and Gardner, F. (1950). Brit. Heart J., (in the press).

Castellanos, A., Pereiras, R. and Garcia, A. (1938). Presse méd., 46, 1474.

Chavez, I., Dorbeckker, N. and Celis, A. (1947). Amer. Heart J., 33, 560.

Donzelot, E., Eman-Zade, A. M., de Balsac, H., Escalle, J. E. and Antoine, M. (1949). Arch. Mal. Caur, $42,35$.

Forssmann, W. (1931). Munch. med. Wschr., 78, 489.

Gardner, F. (1948). Brit. Heart J., 10, 299.

Goodwin, J. F., Steiner, R. and Wayne, E. J. (1949). Ibid., 11, 279.

Grishman, A., Steinberg, M. F. and Sussman, M. L. (1941). Radiology, 37, 178.

Hills, T. H. (1948). Brit. J. Radiol., 21, 511.

Keele, K. D. (1948). Ibid., 21, 380.

Laubry, C., Cottentot, P., Routier, D. and de Balsac, H. R. (1935). Presse. méd., 43, 2071.

Parkinson, J. (1933). Brit. med. J., 2, 591. (1936). Lancet, 1, 1337 and 1391.

Robb, G. P. and Steinberg, I. (1939). Amer. J. Roentgen., 42, 14.

Roesler, H. (1943) Clinical Roentgenology of the Cardiovascular System, 2nd ed., C. G. Thomas, Baltimore, Maryland.

Steinberg, M. F., Grishman, A. and Sussman, M. L. (1942). Amer. J. Roentgen., 48, 141.

$\longrightarrow,-,(1943 a)$. Ibid., 49, 766.

$\longrightarrow,-,(1943 b)$. Ibid., 50, 306.

(1943c). Amer. J. Dis. Child., 65, 922.

Sussman, M. L., Steinberg, M. F. and Grishman, A. (1944). Amer. Heart J., 28, 647.

, (1946). The Cardiovascular System in Clinical Radiology, edited by G. Y. Pillmore, P. 1-122.

Taylor, H. K. and Shulman, I. (1942). Radiology, 39, 323.

- and McGovern J. (1944). Ibid., 43, 364. 